\title{
Saharan dust event impacts on cloud formation and radiation over Western Europe
}

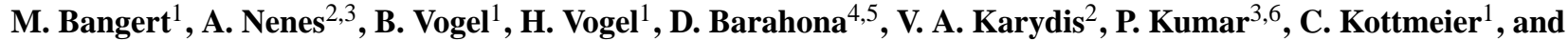 \\ U. Blahak ${ }^{7}$ \\ ${ }^{1}$ Institute for Meteorology and Climate Research, Karlsruhe Institute of Technology, Karlsruhe, Germany \\ ${ }^{2}$ School of Earth and Atmospheric Sciences, Georgia Institute of Technology, Atlanta, GA, USA \\ ${ }^{3}$ School of Chemical and Biomolecular Engineering, Georgia Institute of Technology, Atlanta, GA, USA \\ ${ }^{4}$ Global Modeling and Assimilation Office, NASA GSFC, Greenbelt, MD, USA \\ ${ }^{5}$ I.M. Systems Group, Rockville, MD, USA \\ ${ }^{6}$ SABIC-Innovative Plastics, Selkirk, NY, USA \\ ${ }^{7}$ Deutscher Wetterdienst, Offenbach, Germany
}

Correspondence to: M. Bangert (max.bangert@kit.edu)

Received: 8 November 2011 - Published in Atmos. Chem. Phys. Discuss.: 5 December 2011

Revised: 26 March 2012 - Accepted: 10 April 2012 - Published: 8 May 2012

\begin{abstract}
We investigated the impact of mineral dust particles on clouds, radiation and atmospheric state during a strong Saharan dust event over Europe in May 2008, applying a comprehensive online-coupled regional model framework that explicitly treats particle microphysics and chemical composition. Sophisticated parameterizations for aerosol activation and ice nucleation, together with two-moment cloud microphysics are used to calculate the interaction of the different particles with clouds depending on their physical and chemical properties.
\end{abstract}

The impact of dust on cloud droplet number concentration was found to be low, with just a slight increase in cloud droplet number concentration for both uncoated and coated dust. For temperatures lower than the level of homogeneous freezing, no significant impact of dust on the number and mass concentration of ice crystals was found, though the concentration of frozen dust particles reached up to $1001^{-1}$ during the ice nucleation events. Mineral dust particles were found to have the largest impact on clouds in a temperature range between freezing level and the level of homogeneous freezing, where they determined the number concentration of ice crystals due to efficient heterogeneous freezing of the dust particles and modified the glaciation of mixed phase clouds.

Our simulations show that during the dust events, ice crystals concentrations were increased twofold in this temperature range (compared to if dust interactions are neglected).
This had a significant impact on the cloud optical properties, causing a reduction in the incoming short-wave radiation at the surface up to $-75 \mathrm{~W} \mathrm{~m}^{-2}$. Including the direct interaction of dust with radiation caused an additional reduction in the incoming short-wave radiation by 40 to $80 \mathrm{~W} \mathrm{~m}^{-2}$, and the incoming long-wave radiation at the surface was increased significantly in the order of $+10 \mathrm{~W} \mathrm{~m}^{-2}$.

The strong radiative forcings associated with dust caused a reduction in surface temperature in the order of -0.2 to $-0.5 \mathrm{~K}$ for most parts of France, Germany, and Italy during the dust event. The maximum difference in surface temperature was found in the East of France, the Benelux, and Western Germany with up to $-1 \mathrm{~K}$. This magnitude of temperature change was sufficient to explain a systematic bias in numerical weather forecasts during the period of the dust event.

\section{Introduction}

Aerosol particles are an important part of the atmosphere. They directly modify the planetary radiation budget by scattering and absorption of long and shortwave radiation, and they affect the properties of clouds. Depending on their size and chemical composition, aerosol particles can act as cloud condensation nuclei, $\mathrm{CCN}$, and ice nuclei, IN, and 
profoundly impacting the cloud microphysical processes and optical properties, hence the hydrological cycle and climate.

The complexity of the interactions of aerosol particles with radiation and the hydrological cycle render the most uncertain factors in climate studies and weather prediction.

One of the major contributors to the atmospheric aerosol mass is mineral dust (D'Almeida, 1986). Even though the emission sources of mineral dust in the atmosphere are mainly desert regions, dust particles can be transported over long distances (e.g. Swap et al., 1996; Goudie and Middleton, 2001; Tegen, 2003). Europe and the Mediterranean can be strongly affected by dust outbreaks originating in the Sahara Desert (Ansmann et al., 2003; Wiacek et al., 2010). Dust particles modify the atmospheric radiation balance (Cavazos et al., 2009), which can cause a cooling or heating of the surface depending on several factors like the surface albedo and the elevation of the dust layer (Cavazos et al., 2009; Yin and Chen, 2007; Stanelle et al., 2010). Including the interaction of mineral dust with radiation in model systems used for numerical weather prediction has the potential to improve the quality of the forecast. For example in North Africa, although the background levels may be well represented by climatologies, there are strong dust storms affecting the radiation balance which are significantly underestimated by climatologies and in regions like Europe and the Mediterranean where the dust concentrations are dominated by sporadic Saharan dust events (Perez et al., 2006; Chaboureau et al., 2011).

Mineral dust particles are efficient IN (e.g. Field et al., 2006; Möhler et al., 2006). Since homogeneous freezing of deliquescent aerosol is very unlikely for temperatures higher than $-35^{\circ} \mathrm{C}$, the ice nucleation in the troposphere strongly depends on the heterogeneous freezing involving IN (Cantrell and Heymsfield, 2005). In an eleven year lidarderived cloud data set, Seifert et al. (2010) found a $30 \%$ higher amount of ice containing clouds over Europe with cloud top temperatures from -10 to $-20^{\circ} \mathrm{C}$ in air masses that contained Saharan dust. Analyzing a Saharan dust outbreak over the Atlantic in 2004, Min and Li (2010) showed that ice clouds tend to form at higher temperatures when dust particles are present. Global modelling studies demonstrated the important contribution of mineral dust to IN (e.g. Hoose et al., 2008; Lohmann and Diehl, 2006). The impact of mineral dust on the formation of cirrus clouds for temperatures lower than $-35^{\circ} \mathrm{C}$ depends on the competition of the heterogeneous freezing of mineral dust with the homogeneous freezing of liquid aerosol particles. For conditions with low updraft velocities, the heterogeneous freezing of dust particles is able to inhibit the homogeneous freezing and cause a decrease in ice crystal number concentration of the affected cirrus clouds (Barahona et al., 2010b).

Based on satellite remote sensing, Min et al. (2009) showed that mineral dust significantly increases ice crystal number concentration and cloud droplet concentration with the consequence of a decreasing precipitation rate. Simi- lar results were found by Rosenfeld et al. (2001) with a decrease in cloud droplet radius in clouds affected by dust and a suppression of light precipitation. In contrast, Pradelle and Cautenet (2002) found a decrease in cloud albedo in the presence of mineral dust because of an increase in cloud droplet radius. These conflicting results indicate that the impact of mineral dust on cloud droplet number depends on the individual atmospheric conditions, e.g. background aerosol and cloud type. A case study performed for the Eastern Mediterranean by Solomos et al. (2011) showed an increase in droplet number and in cloud top height with an increasing concentration of mineral dust particles, but also a strong dependency of the dust impact on precipitation on the prescribed aerosol background conditions.

The impact of dust on the cloud droplet concentration in most studies was hypothesized to be caused by hygroscopic coatings, which make them important $\mathrm{CCN}$ due to their large size. With the exception of dust from dry lake beds, freshly emitted dust contains little soluble material (Kumar et al., 2011). Processing of dust particles in clouds (Levin et al., 1996) and the condensation of acids on the particles (Sullivan et al., 2007) are prime mechanisms thought of creating hygroscopic coatings on dust. Uncoated dust was long thought to be a potential CCN (e.g. Pruppacher and Klett, 1997), a theory sufficiently constrained by observations for use in models was lacking. Kumar et al. (2011) showed that through the process of water adsorption, uncoated dust from major global source regions exhibits considerable and consistent $\mathrm{CCN}$ activity. In a recent global modeling study, Karydis et al. (2011) pointed out that even uncoated mineral dust can contribute significantly to cloud droplet number close to the source regions and that hygroscopic coating of dust particles can decrease the cloud droplet number in regions which are affected by anthropogenic emissions due to a decrease in water supersaturation.

This study focuses on a major dust event that occurred in May 2008. Its origin was in the Sahara and from there mineral dust particles were transported over the Western Mediterranean, covering large areas of Western Europe. During the episode, high aerosol concentrations were observed throughout Europe; IN concentrations significantly increased (compared to pre-event levels) at Kleiner Feldberg, Germany (Klein et al., 2010). During this time, traditional weather forecast models exhibited poor prediction skill. The German national meteorological service (Deutscher Wetterdienst, DWD) detected a significant bias in their numerical weather forecast of the $2-\mathrm{m}$ temperatures of $+1.5 \mathrm{~K}$ when the dust outbreaks reached SW-Germany (U. Damrath, DWD, personal communication, 2010, Fig. 1). The operational weather forecast at DWD is performed with the model system COSMO (Consortium for Small-scale Modeling) (Baldauf et al., 2011). Since the impact of aerosol particles on atmospheric state is accounted for in COSMO by using prescribed profiles for aerosol optical properties and prescribed cloud droplet and ice crystal numbers, extraordinary aerosol 
conditions like the dust event in May 2008 are not represented in the simulations. This can potentially cause biases in the weather forecast.

The impacts of dust on atmospheric state are studied with the regional scale online-coupled model system COSMOART (Vogel et al., 2009) that accounts for feedbacks between chemistry, aerosols, radiation, and clouds. A twomoment cloud microphysics scheme (Seifert and Beheng, 2006) is coupled together with comprehensive parameterizations for aerosol activation (Kumar et al., 2009; Barahona et al., 2010a) and ice nucleation (Barahona and Nenes, $2009 \mathrm{~b}$ ) to simulate the impact of the various aerosol particles on the cloud microphysics and therefore on cloud properties and precipitation. This framework can quantify the impact of dust on atmospheric state, as it considers the competition of dust with other aerosol particles during cloud formation and the feedback processes related to cloud microphysics, radiation, and precipitation. The framework is also used to thoroughly study the sensitivity of predicted atmospheric state to the dust amount, properties (hygroscopicity), and parameterization.

\section{The model framework}

The online-coupled regional model system COSMO-ART was extended with two-moment cloud microphysics and comprehensive parameterizations for aerosol activation and ice crystal nucleation. COSMO-ART is based on the operational weather forecast model COSMO (Baldauf et al., 2011) of the Deutscher Wetterdienst (DWD) which was online coupled with comprehensive modules for gas phase chemistry and aerosol dynamics. An extended version of MADEsoot (Riemer et al., 2003) is used to represent the aerosol population with eleven overlapping lognormal modes. Five modes represent sub-micron particles consisting of sulphate, ammonium, nitrate, organic compounds, water, and soot in a range of mixing states. These modes are coupled with the gas phase by condensation and nucleation, and are strongly influenced by anthropogenic emissions of gases and particles. Sea salt and mineral dust particles are represented by three modes (Table 1) in each case. The model includes a comprehensive photochemical module to capture the temporal and spatial distributions of inorganic and semi-volatile organic compounds. The emission of sea salt is calculated online in the model as a function of $10 \mathrm{~m}$-windspeed and sea surface temperature (Lundgren, 2010). The emission of dust particles is calculated according to Vogel et al. (2006) as a function of friction velocity, soil water content, and surface roughness by combining the parameterization of the saltation processes after (Alfaro and Gomes, 2001) with the treshold friction velocity of Lu and Shao (1999). The treatment of the soil parameters, which are crucial for the calculation of the dust emissions, are described by Stanelle et al. (2010). A detailed description of the treatment of gases, aerosols, and their emissions is given by Vogel et al. (2009) and an evaluation of the simulated gas phase and aerosol characteristics for Europe is found in Knote et al. (2011).

\subsection{Cloud microphysics}

COSMO includes an efficient bulk cloud microphysics scheme, designed for operational weather forecast (Doms et al., 2005). This scheme cannot treat aerosol-cloud interactions, because only one moment of the size distribution is calculated. Bangert et al. (2011) extended the cloud scheme to a two-moment representation of the cloud droplet size distribution to consider the impact of aerosol particles on warm cloud microphysics. To further improve the clouds microphysics and to enable the simulation of aerosol impacts on ice clouds a comprehensive two-moment bulk microphysical scheme (Seifert and Beheng, 2006; Seifert et al., 2006; Noppel et al., 2006; Blahak, 2008) was introduced, which replaces the old schemes. This scheme distinguishes six hydrometeor categories (cloud drops, cloud ice, rain, snow, graupel, and hail) and represents each particle type by its respective number and mass concentration. A (generalized) gamma size distribution is used for each hydrometeor class, where the so-called shape parameters are held constant during the simulation. For the warm clouds, the scheme considers autoconversion of cloud droplets to rain, accretion of cloud droplets by rain drops, self-collection of cloud and rain droplets, break-up of rain drops, and evaporation of rain drops. Condensational growth of cloud droplets is calculated with a saturation adjustment technique. For the cold clouds, homogeneous and heterogeneous ice nucleation, diffusional growth of ice crystals, freezing of cloud and rain droplets, aggregation, self-collection, riming, conversion to graupel, melting, sublimation, shedding, and Hallett-Mossop ice multiplication are considered. The freezing of cloud and rain drops is calculated with a classical statistical approach based on an empirical relation for the freezing probability as a function of temperature (Seifert and Beheng, 2006). Note that the freezing of cloud and rain droplets is independent of the simulated IN concentrations. This may introduce an underestimation of the glaciation of mixed phase clouds for high IN concentrations, but can be justified by a small fraction of cloud droplets originating from activated dust particles in our simulations. A detailed description of the cloud microphysical processes is given in Seifert and Beheng (2006), and a statistical analysis of the aerosol-cloud interaction for three summer seasons using the microphysics scheme is presented in Seifert et al. (2011).

Although COSMO is a non-hydrostatic model and therefore permits the simulation of convection, a parameterization of subgrid-scale deep convection has to be used for coarse model resolutions. We use a modified Tiedtke scheme (Tiedtke, 1989) for horizontal resolutions coarser than $7 \mathrm{~km}$, which considers the convective transport of gases and aerosol particles. 
Table 1. Overview of the individual aerosol modes, their chemical composition (first block), the involved cloud interaction processes (second block), aerosol dynamical processes (third block), and their initial diameter and standard deviation (fourth block). The model framework includes secondary aerosol and soot modes (if, ic, jf, jc, and s), sea salt modes (sa, sb, and sc) and dust modes (da, db, and dc).

\begin{tabular}{|c|c|c|c|c|c|c|c|c|c|c|c|}
\hline & if & ic & jf & $\mathrm{jc}$ & $\mathrm{s}$ & sa & $\mathrm{sb}$ & $\mathrm{sc}$ & da & $\mathrm{db}$ & $\mathrm{dc}$ \\
\hline Inorg. salts & - & $\bullet$ & $\bullet$ & $\bullet$ & & $\bullet$ & $\bullet$ & $\bullet$ & & & \\
\hline Organics & $\bullet$ & $\bullet$ & $\bullet$ & $\bullet$ & & & & & & & \\
\hline Soot & & $\bullet$ & & $\bullet$ & $\bullet$ & & & & & & \\
\hline Dust & & & & & & & & & $\bullet$ & $\bullet$ & $\bullet$ \\
\hline Activation (Köhler) & $\bullet$ & $\bullet$ & $\bullet$ & $\bullet$ & & $\bullet$ & - & $\bullet$ & & & \\
\hline Activation (FFH) & & & & & $\bullet$ & & & & $\bullet$ & $\bullet$ & $\bullet$ \\
\hline Activation (Unified) & & & & & & & & & $\bullet$ & $\bullet$ & $\bullet$ \\
\hline Homogeneous freezing & $\bullet$ & & $\bullet$ & & & $\bullet$ & $\bullet$ & $\bullet$ & & & \\
\hline Heterogeneous freezing & & $\bullet$ & & $\bullet$ & $\bullet$ & & & & $\bullet$ & $\bullet$ & $\bullet$ \\
\hline Coagulation & $\bullet$ & $\bullet$ & $\bullet$ & $\bullet$ & $\bullet$ & & & & & & \\
\hline \multirow[t]{5}{*}{ Condensation } & $\bullet$ & $\bullet$ & $\bullet$ & $\bullet$ & $\bullet$ & & & & & & \\
\hline & \multicolumn{11}{|c|}{ Initial diameter in $\mu \mathrm{m}$} \\
\hline & 0.01 & 0.08 & 0.07 & 0.08 & 0.08 & 0.2 & 1 & 12 & 1.5 & 6.7 & 14.2 \\
\hline & \multicolumn{11}{|c|}{ Standard deviation } \\
\hline & 1.7 & 2 & 1.7 & 2 & 1.4 & 1.9 & 2 & 1.7 & 1.7 & 1.6 & 1.5 \\
\hline
\end{tabular}

Table 2. Overview of the setup for the nested simulations. The interaction involving aerosol include anthropogenic (if, ic, jf, jc, and s) and sea salt (sa, sb, and sc) modes, whereas dust refers to the dust modes (da, db, and dc) only.

\begin{tabular}{lccccc}
\hline Interactions & REF & R & C & $\mathrm{C}^{*}$ & $\mathrm{CR}$ \\
\hline Cloud-radiation & $\bullet$ & $\bullet$ & $\bullet$ & $\bullet$ & $\bullet$ \\
Aerosol-radiation & $\bullet$ & $\bullet$ & $\bullet$ & $\bullet$ & $\bullet$ \\
Aerosol-water clouds & $\bullet$ & $\bullet$ & $\bullet$ & $\bullet$ & $\bullet$ \\
Aerosol-ice clouds & $\bullet$ & $\bullet$ & $\bullet$ & $\bullet$ & $\bullet$ \\
Dust-water clouds (FFH theory) & & & $\bullet$ & & $\bullet$ \\
Dust-water clouds (Unified theory) & & & & $\bullet$ & \\
Dust-ice clouds & & & $\bullet$ & $\bullet$ & $\bullet$ \\
Dust-radiation & & $\bullet$ & & & $\bullet$ \\
\hline
\end{tabular}

\subsection{Aerosol activation}

The activation of an aerosol particle to a cloud droplet depends on its ability to remain in a stable equilibrium with the ambient water vapor. The water vapor saturation ratio, $S_{\mathrm{eq}}$, of an aerosol particle in equilibrium with surrounding water vapor can be expressed as

$S_{\mathrm{eq}}=\alpha_{\mathrm{w}} e^{\frac{4 \sigma M_{\mathrm{w}}}{R \rho_{\mathrm{w}} D}}$,

where $\sigma$ is the surface tension at the particle-gas interface, $M_{\mathrm{w}}$ is the molar mass of water, $R$ is the universal gas constant, $T$ is the temperature, $\rho_{\mathrm{w}}$ is the density of water, and $D$ is the equivalent particle diameter. The exponential in Eq. (1) is commonly referred to as the curvature or Kelvin effect. $\alpha_{\mathrm{w}}$ is the activity of the water and depends on the physiochemical properties of the particle. In case of a soluble aerosol particle $\alpha_{\mathrm{w}}$ can be expressed by the effective mole fraction of water in the solution droplet, which results in the well known Köhler equations. For insoluble particles (e.g. dust) this classical theory cannot be applied, because $S_{\text {eq }}$ is now affected by another physical process namely the process of physisorption of water vapor on the particle surface. In this case $\alpha_{\mathrm{w}}$ can be determined by FHH (Frenkel, Halsey, and Hill) adsorption theory (e.g. Lowell et al., 2004)

$\alpha_{\mathrm{W}}=e^{-A_{\mathrm{FHH}} \Theta^{-B_{\mathrm{FHH}}}}$,

where $A_{\mathrm{FHH}}, B_{\mathrm{FHH}}$ are empirical constants, and $\Theta$ is the surface coverage (defined as the number of adsorbed layers of water). $A_{\mathrm{FHH}}$ characterizes interactions of adsorbed molecules with the aerosol surface and adjacent adsorbate molecules (i.e. those in the first monolayer). $B_{\mathrm{FHH}}$ characterizes the attraction between the aerosol surface and the adsorbate in subsequent layers; the smaller the value of $B_{\mathrm{FHH}}$, the greater the distance at which the attractive forces act (Sorjamaa and Laaksonen, 2007). $A_{\mathrm{FHH}}$ and $B_{\mathrm{FHH}}$ are compound-specific and determined experimentally. Both theories (Köhler and FHH) show a similar behavior for $S_{\text {eq }}$, with a characteristic maximum (the critical supersaturation $s_{\mathrm{c}}$ ). For ambient supersaturations greater than $s_{\mathrm{c}}$ the particle can get activated and grow to the size of a cloud droplet.

In this study we use a comprehensive activation parameterization (Kumar et al., 2009; Barahona et al., 2010a) based on a cloud parcel framework, in which a parcel of air containing an external mixture of Köhler and FHH particles is lifted. At first the $s_{\mathrm{c}}$ distribution is calculated for each aerosol. Then the supersaturation equation of the parcel is solved using the bisection method to determine the maximum supersaturation, $s_{\max }$, and the number of activated particles, $N_{\mathrm{a}}^{*}$. As input 
data the simulated cloud-scale dynamics (updraft, temperature, pressure) and aerosol properties (size distributions and chemical compositions of all aerosol modes) are used.

To account for hygroscopic coating of e.g. dust particles, Kumar et al. (2011) developed a unified activation theory by merging Köhler and FHH theory in their parameterization. For coated dust particles $\alpha_{\mathrm{w}}$ is represented by

$\alpha_{\mathrm{w}}=x_{\mathrm{w}} \gamma_{\mathrm{w}} e^{-A_{\mathrm{FHH}} \Theta^{-B_{\mathrm{FHH}}}}$,

where $x_{\mathrm{w}} \gamma_{\mathrm{w}}$ is the mole fraction and activity coefficient of water in the droplet and represents the solute effects on water activity.

Based on the procedure of Bangert et al. (2011) the activation rate, ACT, of aerosol particles in the model is calculated in different ways, replacing the activation rate in Eq. (17) of Seifert and Beheng (2006). For a newly formed cloud the parameterization is directly applied and $N_{\mathrm{a}}^{*} / \Delta t$ equals the activation rate, where $\Delta t$ is the time step used. In case of an already existing cloud the activation rate at the cloud base is calculated on the basis of advection and turbulent diffusion of particles into the cloud base

$\mathrm{ACT}=-\frac{\partial}{\partial z} N_{\mathrm{a}}^{*}\left(s_{\max }\right) w+\frac{\partial}{\partial z} K \frac{\partial}{\partial z} N_{\mathrm{a}}^{*}\left(s_{\max }\right)$,

where $w$ is the grid-scale updraft, $z$ is the height above sea level, and $K$ is the turbulent diffusion coefficient.

In-cloud activation is calculated, if the simulated gridscale supersaturation increases again above the cloud base, e.g. from strong updrafts. In this case, the growth of the existing cloud droplets is considered by assuming they act as giant $\mathrm{CCN}$ that deplete supersaturation by the approach of Barahona et al. (2010a). The corresponding activation rate is calculated as $N_{\mathrm{a}}^{*} / \Delta t$.

\subsection{Ice nucleation}

The nucleated number concentration of ice crystals, $N_{\mathrm{i}}^{*}$, is calculated using the parameterization of Barahona and Nenes (2008, 2009a,b), which is based on the framework of an ascending Lagrangian air parcel. Competition between homogeneous and heterogeneous freezing is explicitly considered in the calculation of the ice supersaturation, $s_{\mathrm{i}}$. In doing so the dependency of $N_{\mathrm{i}}^{*}$ on the conditions of cloud formation (i.e. $T, p$ ), updraft velocity, deposition coefficient, and soluble and insoluble aerosol concentrations is explicitly resolved. $N_{\mathrm{i}}^{*}$ is given by

$N_{\mathrm{i}}^{*}=\left\{\begin{array}{ll}N_{\text {hom }}+N_{\text {het }}\left(s_{\text {hom }}\right) ; & N_{\text {het }}\left(s_{\text {hom }}\right)<N_{\text {lim }} \\ N_{\text {het }}\left(s_{\text {i, max }}\right) ; & N_{\text {het }}\left(s_{\text {hom }}\right) \geq N_{\text {lim }}\end{array}\right.$,

where $s_{\mathrm{i}, \max }$ is the maximum supersaturation that develops in the cirrus, $s_{\text {hom }}$ is the homogeneous freezing threshold (Koop et al., 2000), and $N_{\text {hom }}$ and $N_{\text {het }}$ are the number of ice crystals forming from homogeneous and heterogeneous freezing, respectively. $N_{\mathrm{lim}}$ is the IN concentration

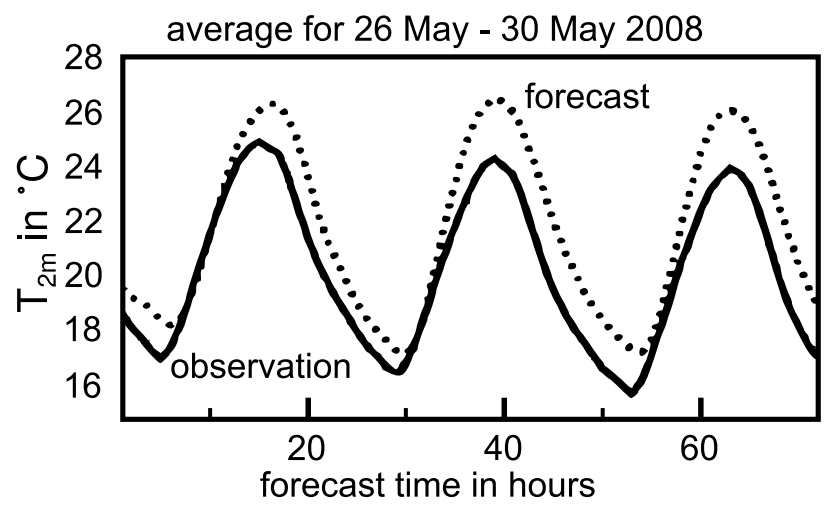

Fig. 1. Predicted $T_{2} \mathrm{~m}$ as a function of forecast hour compared with measurements for the area of SW-Germany (see area $\Omega$ in Fig. 2). Each day a forecast for three days was simulated; afterwards the results and the corresponding observations were averaged as a function of forecast hour to identify systematic differences between forecast and observation (U. Damrath, DWD, personal communication, 2010).

that completely inhibits homogeneous nucleation and sets the limit between combined heterogeneous-homogeneous freezing and pure heterogeneous freezing only. $N_{\text {lim }}$ is explicitly calculated as a function of cloud formation conditions and is related to the slope of the IN spectrum, $N_{\text {het }}\left(s_{\mathrm{i}}\right)$ (Barahona and Nenes, 2009a).

The heterogeneous freezing spectrum of Phillips et al. (2008) is used for $N_{\text {het }}\left(s_{\mathrm{i}}\right)$, which is derived from several field campaign data sets. It provides the contribution of individual aerosol species (dust, black carbon, and organics) and freezing mechanisms (e.g. immersion and deposition) to $N_{\text {het }}\left(s_{\mathrm{i}}\right)$. The contribution of the individual dust modes to $N_{\text {het }}\left(s_{\mathrm{i}}\right)$ is scaled to their surface area distribution (Barahona and Nenes, 2009a). Niemand et al. (2012) compared different parameterizations of immersion freezing of dust. They showed that applying the heterogeneous freezing spectrum of Phillips et al. (2008) on dust concentrations simulated with COSMO-ART, the measured IN concentrations at Kleiner Feldberg during the dust event were reproduced.

The homogeneous contribution to $N_{\mathrm{i}}^{*}$ is given by

$N_{\mathrm{hom}}=\left\{\begin{array}{ll}N_{0} e^{-f_{\mathrm{c}}}\left(1-e^{-f_{\mathrm{c}}}\right) & f_{\mathrm{c}}<0.6 \\ N_{0}\left[1+e^{\left(\frac{9-2 f_{\mathrm{c}}}{7}\right)}\right]^{-1} & f_{\mathrm{c}} \geq 0.6\end{array}\right.$,

where $N_{0}$ is the number concentration of the supercooled liquid droplet population and $f_{\mathrm{c}}$ is the droplet freezing fraction for cirrus clouds formed in situ (Barahona and Nenes, 2008). $N_{0}$ equals the sum of the number concentration of the soluble aerosol modes (Table 1) which are assumed to deliquesce during ice cloud formation. 
The nucleation rate of ice crystals, NUC, is calculated following Seifert and Beheng (2006) Eq. (34) by

$\mathrm{NUC}=\max \left(\frac{N_{\mathrm{i}}^{*}-N_{\mathrm{i}}}{\Delta t}, 0\right)$,

where $N_{\mathrm{i}}$ is the number concentration of ice crystals before the nucleation pulse.

\subsection{Subgrid-scale updrafts}

Though regional models are able to resolve individual cloud systems, they cannot explicitly capture the updraft velocities which control nucleation of ice and droplets. Therefore parameterizations of the subgrid-scale vertical velocity must be applied to address this issue.

Sub-grid scale vertical velocities, $w^{\prime}$, are described with a Gaussian probability distribution function, $P_{w}\left(w^{\prime}\right)$. The mean of $P_{w}\left(w^{\prime}\right)$ is set equal to the grid scale updraft, $w$, and the standard deviation, $\sigma_{w}$, is calculated as the square root of the turbulent kinetic energy (Morales and Nenes, 2010). A weighted mean of the activated particles/nucleated ice crystals, $N_{x}^{*}$, is calculated by numerically calculating the integral

$N_{x}^{*}=\frac{\int_{0}^{\infty} N_{x}^{*}\left[s_{\max }\left(w^{\prime}\right)\right] P_{w}\left(w^{\prime}\right) d w^{\prime}}{\int_{0}^{\infty} P_{w}\left(w^{\prime}\right) d w^{\prime}}$.

\subsection{Radiation}

The radiative fluxes are calculated with the GRAALS (Ritter and Geleyn, 1992) radiation scheme of COSMO for eight spectral bands. To consider the impact of varying aerosol and clouds the necessary optical properties, as they are the extinction coefficient, single scattering albedo, and asymmetry factor, have to be calculated.

The optical properties of the aerosol particles are calculated as a function of the size distributions, the chemical composition, as well as the soot and water content with the parameterizations of Vogel et al. (2009), Lundgren (2010), and Stanelle et al. (2010).

The optical properties used for the dust particles are calculated based on measurements of the shortwave refractive indexes during the SAMUM (Saharan Mineral dUst experiMent) campaign and the longwave refractive indexes used in Helmert et al. (2007), where a mineralogical composition of $98 \%$ Kaolinite and $2 \%$ Hematite is assumed. A priori Mie calculations for the three different dust modes were carried out to derive the individual mass specific extinction coefficient, single-scattering albedo and asymmetry factor for the eight spectral bands of GRAALS. The actual optical properties are calculated online for each dust mode based on the a priori derived values and the simulated dust mass concentration. A detailed description of the parameterization is given by Stanelle et al. (2010).

To consider the varying droplet and ice crystal size in the radiation scheme the parameterizations of $\mathrm{Hu}$ and Stamnes

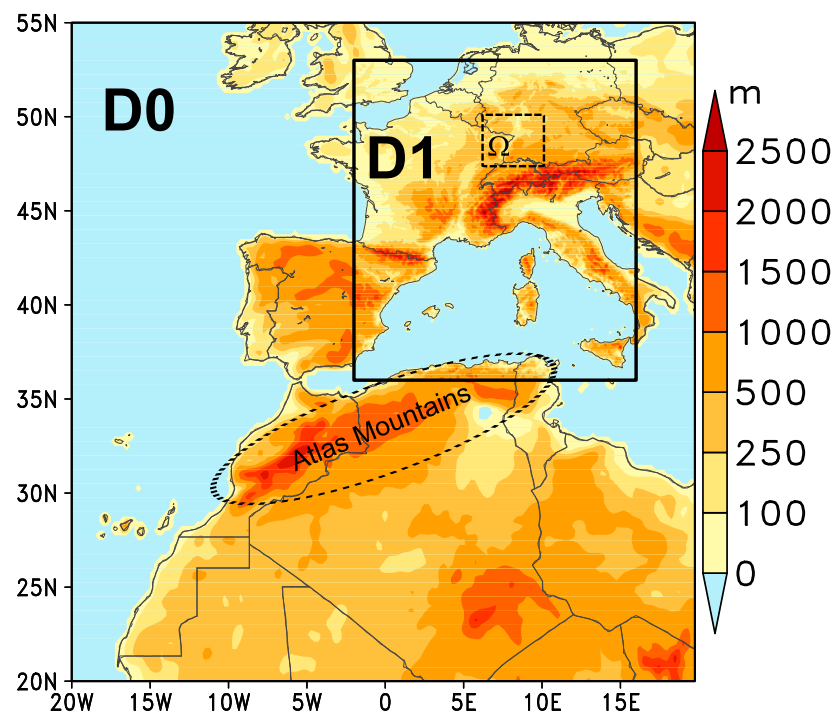

Fig. 2. Terrain height within the model domains D0 and D1.

(1993) and Edwards et al. (2007) are applied to calculate the optical properties of the cloud droplets and ice crystals. Here the effective radii of clouds droplets, $r_{\mathrm{c}}$, and ice crystals, $r_{\mathrm{i}}$, are calculated as the ratio of the third to second moment of the respective size distribution. The adaption of the parameterizations for the eight spectral bands of GRAALS is carried out following Zubler et al. (2011). Precipitating hydrometeors of snow, graupel, and rain, are not considered in the radiation calculations, which may introduce a bias in the calculated radiation fields (Waliser et al., 2011).

\section{Simulation setup}

A nesting approach is used for the simulations. At first a simulation for a domain D0 covering Northwest Africa and Western Europe was performed. This domain enables the explicit simulation of the dust emissions over Africa and the long-range transport of the dust particles to Europe (Fig. 2). All gases and aerosol particles are simulated (see Sect. 2), but are not allowed to interact with clouds and radiation. Calculations of the cloud microphysical processes are carried out with the one-moment cloud scheme, which includes cloud water, rain, cloud ice, snow, and graupel. The grid size is $0.25^{\circ}(\approx 28 \mathrm{~km})$ in both horizontal directions with 40 nonequidistant levels in the vertical up to an height of $20 \mathrm{~km}$. Initial and boundary conditions for meteorological variables are obtained from the IFS ECMWF analysis; for gas-phase compounds, MOZART-4 results (Emmons et al., 2010) are used. Clear air conditions are assumed for the initial aerosol and for aerosol outside of the domain. The simulation starts at 22 May 2008, 00:00 UTC and ends 30 May 2008, 00:00 UTC.

For the analysis of the aerosol-cloud interaction three simulations were carried out on the nested grid for domain D1 
(Fig. 2) covering regions affected by the dust event (France, Germany, and the Mediterranean). Cloud microphysical processes were simulated with the two-moment scheme (Sect. 2.1) and full interaction with the aerosol particles were allowed. The horizontal grid size is $0.0625^{\circ}(\approx 7 \mathrm{~km})$ in both directions with 40 non-equidistant levels in the vertical up to an height of $20 \mathrm{~km}$ and the simulated period is 22 May, 00:00 UTC till 30 May, 00:00 UTC. The boundary and initial conditions for all prognostic variables are taken from the simulation of the coarse grid for domain D0, which includes the concentration of dust transported from North Africa. The first four days (22 May till 25 May 2008) of the simulation are used to build up the aerosol concentration based on direct emissions and secondary formation. The analysis of the results focuses on the dust event (26 May till 29 May 2008). The individual nested simulations differ in the setup used for the dust-atmosphere interaction. In simulation REF the interaction of dust particles with clouds and radiation was not allowed. To investigate the impact of the dust particles due to their interaction with clouds we carried out simulation C which includes the impact of the dust particles on cloud formation via activation of dust particles and heterogeneous nucleation of cloud ice on the dust particles. In simulation C dust particles are assumed to not have a hygroscopic coating. Therefore the FHH adsorption theory is used for the activation of the dust particles using $A_{\mathrm{FHH}}=2.5$, and $B_{\mathrm{FHH}}=1.2$ (Kumar et al., 2011). Aged dust particles can potentially have hygroscopic coatings which decreases the supersaturation needed for their activation. The aging of dust particles by condensation or chemical reactions is not treated explicitly in COSMO-ART so far. For this reason, simulation $\mathrm{C}^{*}$ is carried out in which we assume that the dust particles are coated by $10 \%$ ammonium sulfate (in volume). In this case the activation of the dust particles is calculated with the unified approach of Kumar et al. (2011). In simulation CR, the direct interaction of the dust particles with long and shortwave radiation is considered additionally to their impact on cloud formation (with the conditions of simulation C). Table 2 gives an overview of the individual simulations and their abbreviations.

In all simulations a detailed data set for anthropogenic emissions, which includes traffic emissions, emissions by large point sources, and area sources such as households and industrial areas, is used. The emission data has an hourly resolution and includes the emission of $\mathrm{SO}_{2}, \mathrm{CO}, \mathrm{NO}_{\mathrm{x}}, \mathrm{NH}_{3}$, 32 individual classes of $\mathrm{VOC}$, and the direct emission of elemental carbon particles (Pregger et al., 2007).

\section{Results}

During the 26 to 30 May 2008 Europe was affected by a strong Saharan dust event. A persistent trough reaching from Iceland to Morocco dominated the synoptic situation during these days. Due to steady southerly winds over

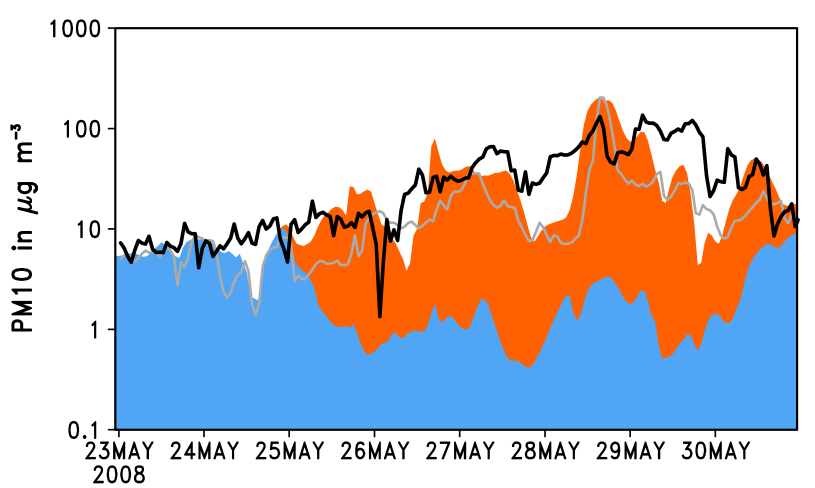

Fig. 3. Measured aerosol mass concentration, $\mathrm{PM}_{10}$, at Hohenpeissenberg (H. Flentje, DWD, personal communication, 2010) (black solid line) and simulated $\mathrm{PM}_{10}$ of the coarse simulation for domain D0 (shadings) and the high resolution simulation for domain D1 (gray solid line, simulation CR). Red shading represents the total aerosol mass concentration of dust particles (mode da and $\mathrm{db}$ ) and blue shading is the total aerosol mass concentration of all other modes (including anthropogenic aerosol particles and sea salt. Please note that the vertical axis is in $\log _{10}$-scale to take the large variation of $\mathrm{PM}_{10}$ during the dust event into account.

the Mediterranean dust particles were transported efficiently from the emission sources in the Sahara to Central Europe. Figure 3 shows the measured and simulated aerosol mass concentration of particles with a diameter below $10 \mu \mathrm{m}$ $\left(\mathrm{PM}_{10}\right)$ at Hohenpeissenberg, Germany (H. Flentje, DWD, personal communication, 2010). The measurements show a strong increase of the aerosol mass starting at 26 May and lasting till 30 May. The simulation attribute this to the arrival of mineral dust transported from the Sahara. The model reproduces the measured $\mathrm{PM}_{10}$ concentrations reasonably well during the dust event and captures the existing aerosol background before the arrival of the dust which is dominated by particles from anthropogenic sources. Upon the arrival of the dust, the simulated $\mathrm{PM}_{10}$ concentration of anthropogenic and biogenic particles decrease from $6 \mu \mathrm{g} \mathrm{m}^{-3}$ to $1 \mu \mathrm{g} \mathrm{m}{ }^{-3}$ and increase again after the dust event. This indicates that the aerosol population during a Saharan dust event over Europe differs strongly from the simple assumption of adding additional dust particles to a typical (continental) aerosol population. Therefore aerosol particles have to be simulated explicitly on the basis of anthropogenic and natural emissions in studies, which address the interaction of dust events with the atmosphere.

A comparison of the distribution of simulated and measured $\mathrm{PM}_{10}$ concentrations (EEA, 2011) is shown in Fig. 4 for the main days of the dust event. The distribution of the dust plume (characterized by $\mathrm{PM}_{10}$ concentrations higher than $20 \mu \mathrm{g} \mathrm{m}^{3}$ ) is captured well in the simulations. A strong gradient in $\mathrm{PM}_{10}$ between France and Germany is found in both the simulation and the measurements. On the 29 May, the maximum of the dust plume is shifted slightly to the 

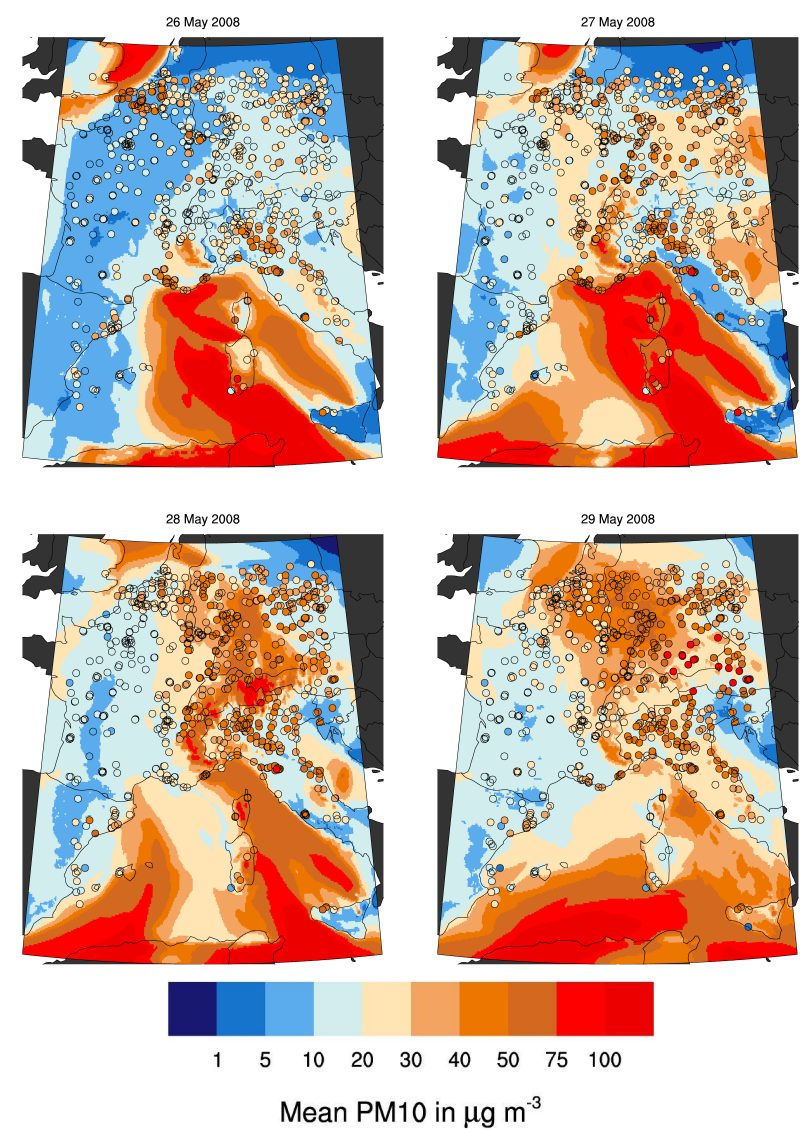

Fig. 4. Simulated average $\mathrm{PM}_{10}$ concentrations in the lowest model layer (case CR, shadings) in comparison to AIRBASE surface PM10 measurements (dots) (EEA, 2011) for the individual days during the dust event.

North West in the simulation in comparison to the observed distribution. In the northern part of of the model domain and in the Po Valley the simulated $\mathrm{PM}_{10}$ concentrations are systematically lower, which is most likely caused by uncertainties in the anthropogenic emission inventory and unresolved local effects.

At the Atlas mountains the transported dust particles were lifted to the upper troposphere. This ascending air flow on the one hand enabled the long range transport of the dust particles to Central Europe and on the other hand caused conditions favorable of heterogeneous and homogeneous ice cloud formation. Additionally, warm and mixed phase clouds were formed over the whole domain.

Figure 5 presents satellite retrievals of MODIS (Menzel et al., 2008) and calculated cloud top temperatures on basis of simulation $\mathrm{C}$ during the morning hours. The cloud top temperature at the individual grid points are calculated as the temperature of the highest model layer in which the grid scale cloud optical thickness exceeds 0.05 . Even though both cloud top temperatures are derived in very different ways, we make a coarse comparison to verify if the main features of the cloud distribution are represented in the simulation. On the morning of the 26 May 2008 the high clouds in the eastern part of the model domain are well captured, whereas the high clouds in the South Western part are not found in the satellite data. On 27 May 2008, the north western part of the model domain is covered by high clouds which is represented in the simulation. The distribution of high clouds on 28 May 2008 shows an eye-catching pattern over the Mediterranean. The high clouds over Eastern France and North Italy on the 29 May 2008 are also represented in the simulation. The main differences on all days are in warm low level clouds which are detected by the MODIS retrieval e.g. over the Mediterranean but are not represented in the simulations. This difference is partly due to a misinterpretation of the MODIS retrieval algorithm which classifies the optical thick dust layers over water as clouds (R. Frey, CIMSS/SSEC/UW-Madison, personal communication, 2011). Differences in the absolute value of cloud top temperatures at very low temperatures most likely arise from the coarse vertical resolution of the model at these heights.

\subsection{Dust plume}

The main dust plume affecting Europe originated in Algeria where steady moderate winds caused an effective emission of mineral dust into the atmosphere. Due to south easterly winds, the dust particles were transported to the North where they were lifted into the middle to upper troposphere at the Atlas Mountains.

Figure 6 presents the simulated daily mean dust number concentrations, $N_{\mathrm{d}}$, for the nested model domain during the period of the dust event. $N_{\mathrm{d}}$ is calculated for three different temperature ranges, each of them favorable for a different process of aerosol cloud interaction. In the lowest layer, which reaches from the ground up to the freezing level, liquid clouds can form, with $N_{\mathrm{d}}$ being highest, up to more than $50 \mathrm{~cm}^{-3}$ inside the plume over the Mediterranean. From 27 May till 29 May 2008 wide areas of Eastern France and Western Germany were affected by dust concentrations above $25 \mathrm{~cm}^{-3}$.

In the middle layer, which reaches from the freezing level up to the level of homogeneous freezing $(T \approx 235 \mathrm{~K}$ ) and hence is favorable for heterogeneous freezing, dust number concentrations are in the order of $10-50 \mathrm{~cm}^{-3}$ with maxima over the eastern part of France.

The upper layer, which reaches from the level of homogeneous freezing up to $15 \mathrm{~km}$ height and hence is favorable of combined homogeneous and heterogeneous freezing, has mean dust concentrations in the order of $1 \mathrm{~cm}^{-3}$ over Europe.

\subsection{Dust impact on cloud droplet and ice crystal number concentration}

Owing to their size and surface properties dust particles can act as $\mathrm{CCN}$. High dust concentrations can therefore 


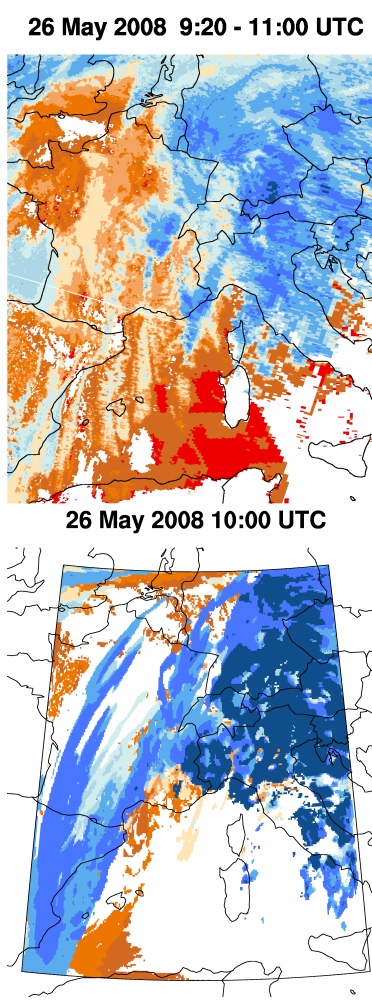

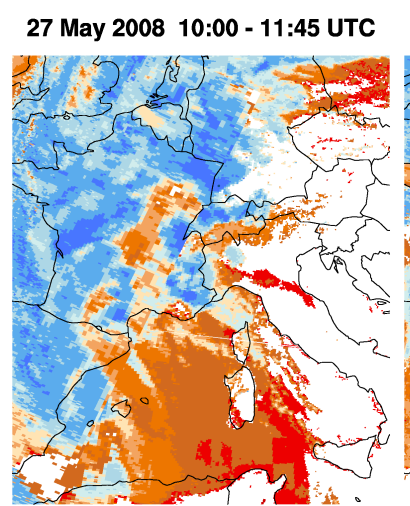

27 May 2008 11:00 UTC

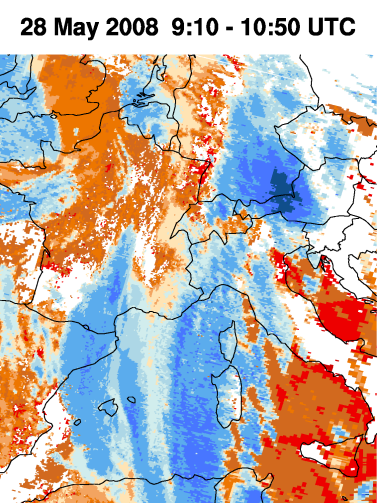

28 May 2008 10:00 UTC
29 May 2008 9:50 - 11:30 UTC

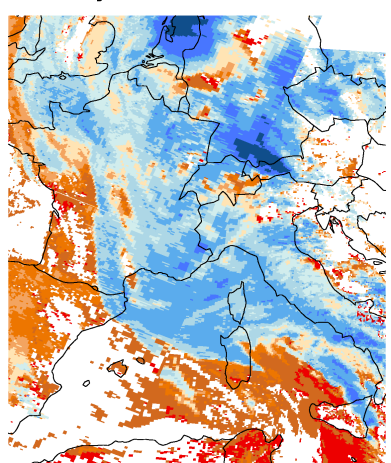

29 May 2008 11:00 UTC
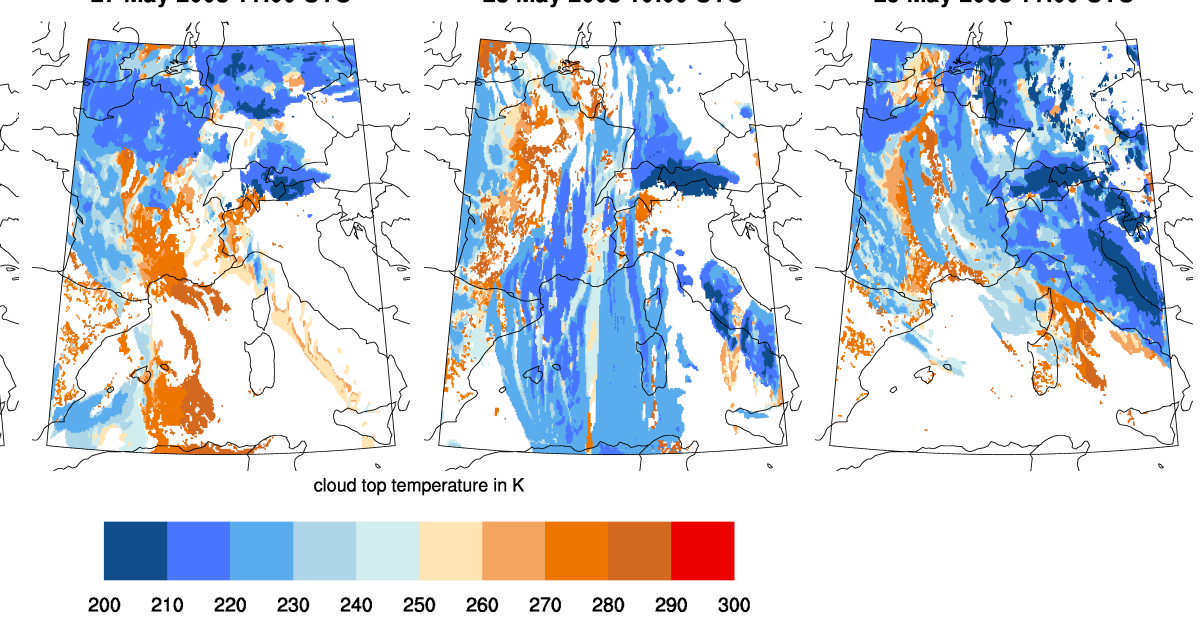

Fig. 5. Composites of cloud top temperatures measured with MODIS (top row) and simulated cloud top temperature (case C, bottom row).

modify the cloud droplet size distribution and consequently the microphysical processes in the warm cloud phase. Dust particles are found to be very efficient ice crystal nuclei in several lab and field studies (Field et al., 2006; Möhler et al., 2006). Ice nucleation due to immersion freezing of dust particles starts at temperature around $263 \mathrm{~K}$ with a freezing fraction on the order of $0.1 \%$. At temperature around $253 \mathrm{~K}$, the freezing fraction of dust particles was found to be in the order of $1 \%$ (Phillips et al., 2008). At temperatures below $235 \mathrm{~K}$ ice crystal nucleation due to homogeneous freezing of aerosol droplets sets in. At this temperature range heterogeneous freezing of the dust particles has to compete with homogeneous freezing for water vapor.

In Fig. 7 joint histograms of cloud droplet and ice crystal number, $N_{\mathrm{c}}$ and $N_{\mathrm{i}}$, and mass concentrations, $m_{\mathrm{c}}$ and $m_{\mathrm{i}}$, are shown for different temperature ranges for simulation REF and $\mathrm{C}$. The histograms are calculated for all grid points and the whole period of the dust event (26-29 May 2008). With the help of the joint histograms, systematic differences in the distribution of $N_{\mathrm{c}}, N_{\mathrm{i}}, m_{\mathrm{c}}$, and $m_{\mathrm{i}}$ between the simulations can be identified together with difference in the overall number of grid points containing cloud water and ice crystals in the individual simulations.
For temperatures above freezing level, the domain-wide joint histograms of cloud droplets in simulation REF and C show small differences. This is because the overall number concentration of available $\mathrm{CCN}$ is dominated by sea salt and secondary aerosol particles. The number concentrations of activated dust particles, $N_{\mathrm{d}}^{*}$, is mostly below $3 \mathrm{~cm}^{-3}$ and higher number concentrations up to $20 \mathrm{~cm}^{-3}$ occurred only for total activated number concentrations, $N_{\mathrm{a}}^{*}$, below $200 \mathrm{~cm}^{-3}$. The fraction of $N_{\mathrm{d}}^{*}$ to $N_{\mathrm{a}}^{*}$ is mostly below $10 \%$.

Despite the fact that the coated dust particles can be activated at lower supersaturations than the uncoated particles, the domain wide joint histogram of cloud droplets in simulation $\mathrm{C}^{*}$ shows only slightly higher $N_{\mathrm{c}}$ in comparison with simulation C (Fig. 7). One reason is that even though much more dust particles get activated in simulation $\mathrm{C}^{*}$ in comparison to simulation $\mathrm{C}$ the number is still low in comparison to the total number of activated particles for most of the grid points (Fig. 8). But we also want to point out here, that there are more cloudy grid points in simulation $\mathrm{C}^{*}$ where $N_{\mathrm{d}}^{*}$ contributes to $10 \%$ or more of $N_{\mathrm{a}}^{*}$ at values of $N_{\mathrm{a}}^{*}$ below $200 \mathrm{~cm}^{-3}$. Hence the dust particles can have a significant impact on individual clouds for conditions with low number concentrations of other aerosol particles. 


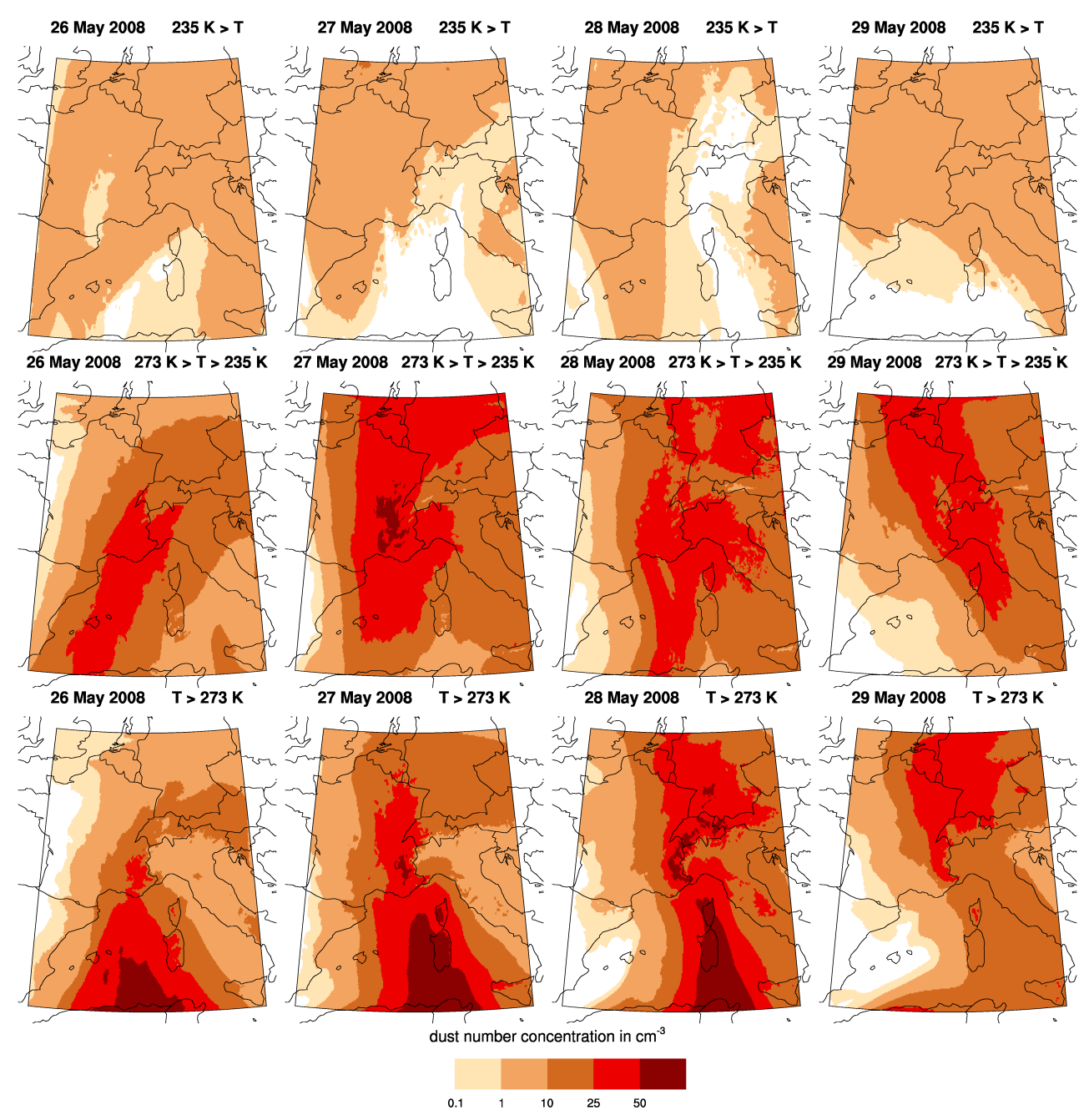

Fig. 6. Simulated daily means of dust number concentrations for atmospheric layers below freezing level (bottom row), layers favorable of heterogeneous freezing (middle row), and layers favorable of homogeneous freezing (top row) for 26-29 May 2008 (columns).

Another reason for the low impact of coated dust particles on $N_{\mathrm{c}}$ is that the increased number of activated dust particles can cause lower maximum supersaturations, $s_{\max }$, due to the growth of the dust particles. This lower supersaturation can result in a decrease of the activated droplets from aerosols other than dust. This can buffer the impact of the increased number of activated dust particles on $N_{\mathrm{c}}$, especially in the case of dust particles with a hygroscopic coating (Kumar et al., 2009), and can be another reason of why total droplet number does not increase significantly in simulation $C^{*}$. In Fig. 9 the joint histogram of the maximum supersaturation and the updraft during the activation process are shown for the cases REF, C, and $\mathrm{C}^{*}$. The impact on $s_{\max }$ is strongest in case $\mathrm{C}^{*}$, with significantly lower $s_{\max }$ in comparison to case REF. Especially the number of gridpoints with $s_{\max }>0.4 \%$ is decreased in case $\mathrm{C}^{*}$ in comparison to case REF. At this gridpoints the concentration of aerosol particles other than dust is low, which explains the susceptibility of $s_{\max }$ to the activation of the dust particles. For uncoated dust particles (case C) the impact on $s_{\max }$ is lower, because of the small amounts of water required for FHH activation (Kumar et al., 2009), in comparison to the Köhler activation of hygroscopic particles.

The impact of the dust particles on number and mass concentration of cloud droplets and ice crystals for atmospheric layers with temperatures in the range of 273 to $235 \mathrm{~K}$ is dominated by the heterogeneous nucleation of ice crystals from dust particles. The joint histogram of number concentrations of ice crystals, $N_{\mathrm{i}}$, and mass concentrations of ice crystals, $m_{\mathrm{i}}$, show a systematic increase in $N_{\mathrm{i}}$ of $301^{-1}$ which corresponds to an increase of $N_{\mathrm{i}}$ in the order of $100 \%$ (Fig. 7). A $N_{\mathrm{i}}$ increase of the order $301^{-1}$ corresponds to roughly $1 \%$ of $N_{\mathrm{d}}$ which nucleate to ice crystals in the considered temperature range. Additionally, the distribution of $N_{\mathrm{i}}$ is broadening 

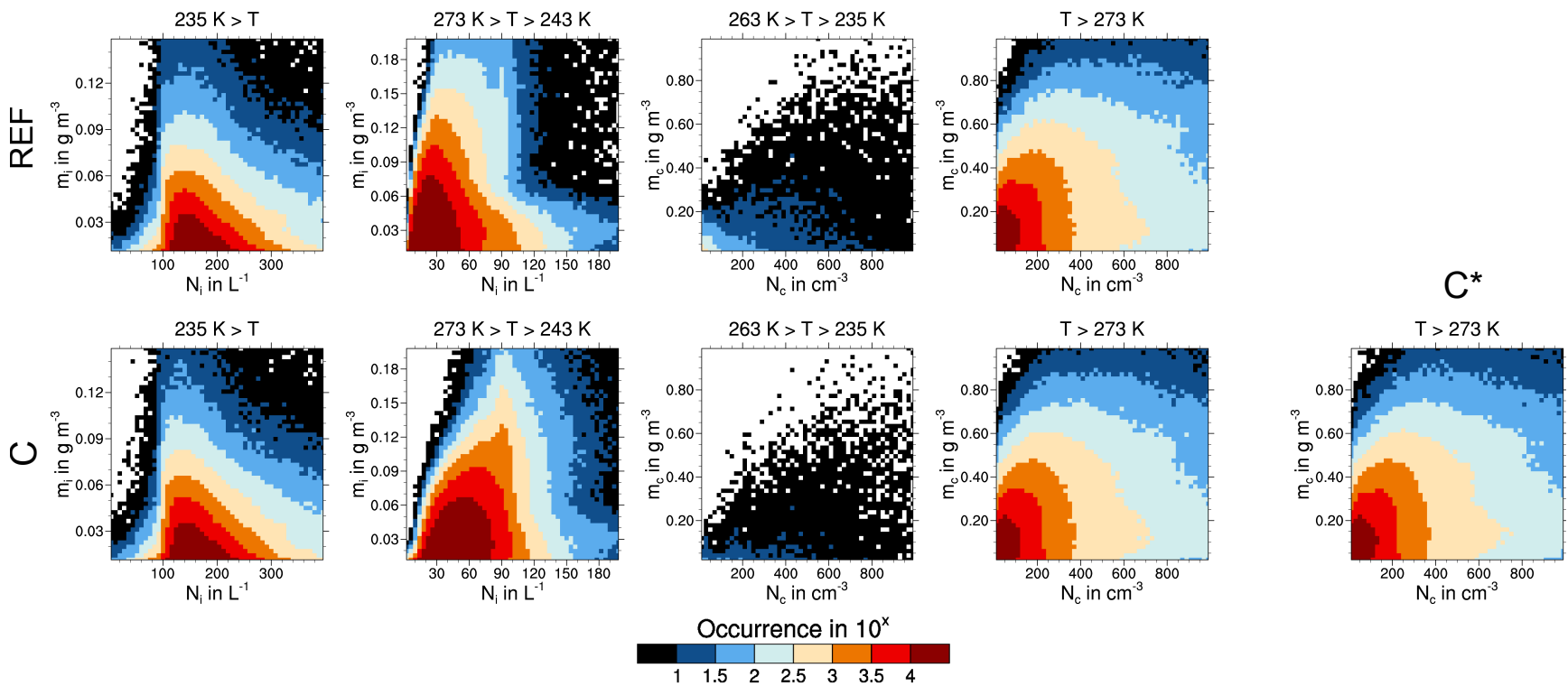

Fig. 7. Domain wide joint histogram of number and mass concentrations for cloud droplet (column 3 to 5) and ice crystals (column 1 to 2) calculated for grid points with $N_{\mathrm{d}} \geq 1 \mathrm{~cm}^{-3}$ and different temperatures ranges for 26-29 May 2008. The top row shows results from simulation REF. The bottom row shows results from simulations $\mathrm{C}$ and $\mathrm{C}^{*}$ (right figure).

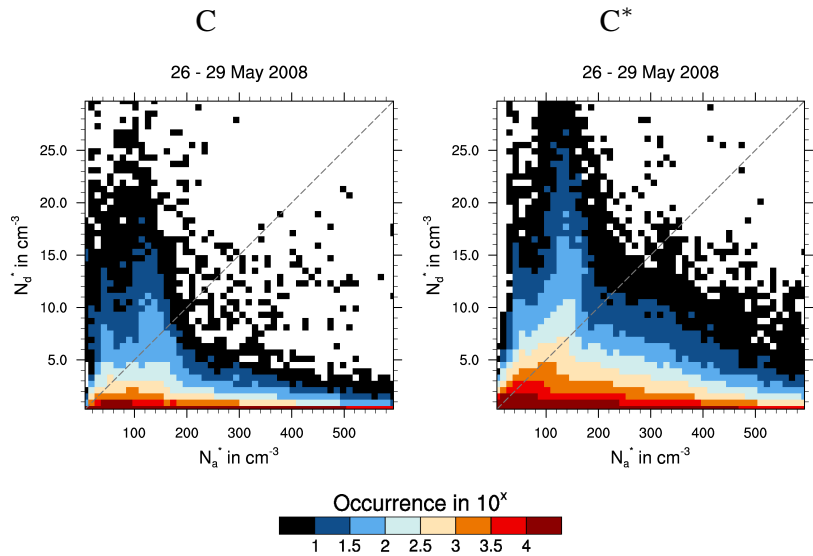

Fig. 8. Domain wide joint histogram of activated dust particles, $N_{\mathrm{d}}^{*}$, and total number of activated aerosol particles, $N_{\mathrm{a}}^{*}$, calculated for grid points with $N_{\mathrm{d}} \geq 1 \mathrm{~cm}^{-3}$ for 26-29 May 2008 for simulation C (left) and $C^{*}$ (right).

from a narrow distribution of $N_{\mathrm{i}}$ in case REF centered at low $N_{\mathrm{i}}$ in the order of $151^{-1}$ to a wide distribution centered at $N_{\mathrm{i}}$ in the order of $60 \mathrm{l}^{-1}$. This can be explained by the more variable distribution of $N_{\mathrm{d}}$ in comparison to the distribution of soot particle IN in case REF.

The more efficient ice nucleation in the temperature range between 273 to $235 \mathrm{~K}$ from heterogeneous freezing of the dust particles has an impact on the glaciation of mixed phase clouds. Though the freezing of cloud droplets in the realized simulations is independent of the simulated aerosol particles, the enhanced ice nucleation involving the dust particles is able to modify the cloud droplet distribution for temperature below $263 \mathrm{~K}$ (Fig. 7). The total number of grid points with $m_{\mathrm{c}}>0$ is significantly reduced in case $\mathrm{C}$ with respect to case REF. In particular, grid points with low $m_{\mathrm{c}}$ and $N_{\mathrm{c}}$ are strongly decreased in number. This is due to the BergeronFindeisen process, where ice crystals grow at the expense of the existing water droplets due to the difference in saturation ratio with respect to water and ice. The total number of grid points containing cloud water decreased by $61 \%$ in simulation $\mathrm{C}$ with respect to simulation REF in the temperature range between 263 to $235 \mathrm{~K}$.

For atmospheric layers above the level of homogeneous freezing $(T<235 \mathrm{~K})$, the joint histograms of $m_{\mathrm{i}}$ and $N_{\mathrm{i}}$ are very similar in both simulations. At this temperature, the heterogeneous freezing of the dust particles has to compete with the homogeneous freezing of the aerosol droplets for water vapor during the ice nucleation. An increasing number of heterogeneous freezing particles, $N_{\text {het }}$, will at first decrease the maximum ice supersaturation during the nucleation event and therefore decrease the total number of nucleated ice crystals because homogeneous freezing is less effective. The value for which $N_{\text {het }}$ completely inhibits homogeneous freezing is defined as $N_{\text {lim }}$ (see Sect. 2.3). For $N_{\text {het }}$ greater than $N_{\text {lim }}$, heterogeneous freezing is the sole contributor to ice crystal number concentration and will increase with increasing $N_{\mathrm{d}}$ (Barahona and Nenes, 2009a). In Fig. 10 the joint histogram of $N_{\text {het }}$ and $N_{\text {lim }}$ is shown for simulation REF and C. In the former, $N_{\text {het }}$ is mostly lower than $101^{-1}$ with only few grid points where $N_{\text {het }}$ exeeds $N_{\text {lim }}$ for conditions with $N_{\text {lim }}$ lower than $601^{-1}$. In the latter simulation, $N_{\text {het }}$ 


\section{REF}

26 - 29 May 2008

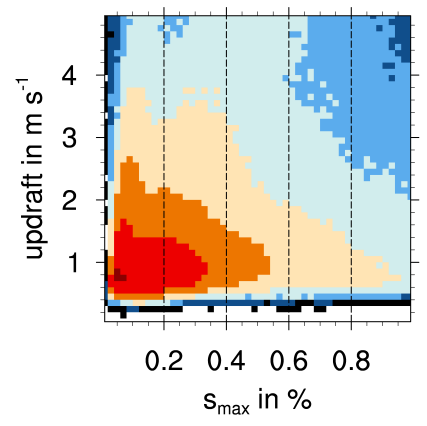

C

26 - 29 May 2008

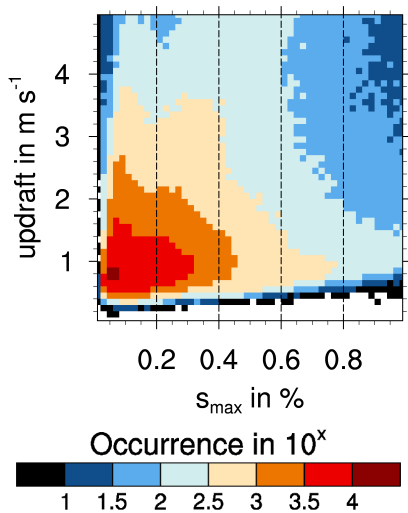

$\mathrm{C}^{*}$

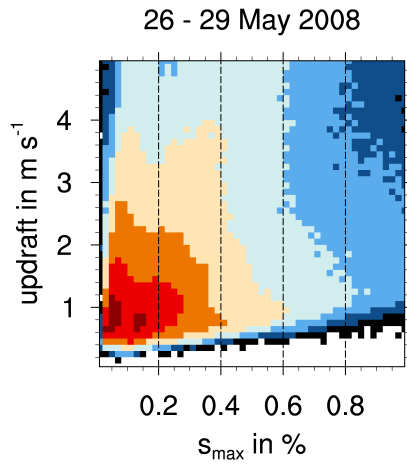

Fig. 9. Joint histogram of updraft and maximum supersaturation, $s_{\max }$, during activation of particles calculated for grid points with $N_{\mathrm{d}} \geq 20 \mathrm{~cm}^{-3}$ for simulation REF (left), C (middle) and $\mathrm{C}^{*}$ (right). The updraft is calculated as $w+\sqrt{T K E}$. $s_{\text {max }}$ is the average of the corresponding updraft PDF (see Eq. 8).

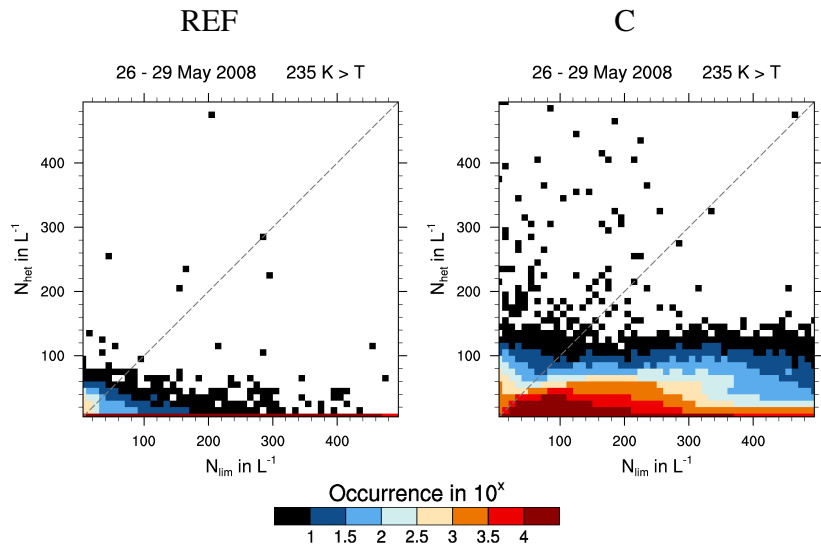

Fig. 10. Joint histogram of heterogeneously nucleated ice crystals and $N_{\text {lim }}$, calculated for grid points with $N_{\mathrm{d}} \geq 0.1 \mathrm{~cm}^{-3}$ for simulation REF (left) and simulation C (right). The dashed line highlights the limit between combined heterogeneous-homogeneous freezing (below the line) and pure heterogeneous freezing only (above the line).

is generally much higher due to the heterogeneous freezing of the dust particles, but rarely exceeds $100 \mathrm{l}^{-1}$. Therefore $N_{\text {het }}$ is mostly below $N_{\text {lim }}$ and is not able to significantly impact $N_{\mathrm{i}}$. For relatively few conditions (with $N_{\text {lim }}$ lower than $\left.1001^{-1}\right) N_{\text {het }}$ is able to exceed $N_{\text {lim }}$.

\subsection{Dust impact on cloud properties and radiation}

In the previous section we focused on the net impact of the dust particles on cloud droplet and ice crystal number concentration for the whole model domain during the simulation period and found systematically higher values in ice crystal number concentration for atmospheric layers between freezing level and the level of homogeneous freezing in case $\mathrm{C}$ in comparison to case REF. This has numerous consequences on cloud properties. We already discussed the more effective glaciation of mixed phase clouds in simulation $\mathrm{C}$, which has potential consequences on the vertical distribution of the latent heat release and the dynamic development of the clouds. The higher number concentrations in $N_{\mathrm{i}}$ (but similar values for $m_{\mathrm{i}}$ ) in both simulations causes difference in the size of the ice crystals and therefore has consequences on the sedimentation velocity of the ice crystals and on the optical properties of the ice clouds. Short wave radiation is scattered more efficiently by smaller ice crystals, which results in optically thicker clouds. In Fig. 11 the difference in the net surface shortwave radiation flux, $F_{\mathrm{sw}}$, around noon at the 26 to 29 May and the difference in the net surface long wave radiation flux, $F_{\mathrm{lw}}$, around midnight at the 26 to 29 May between simulation $\mathrm{C}$ and REF is shown as a function of the vertically averaged $N_{\mathrm{d}}$ at cloud ice containing grid cells in case C. During noon, the distribution of the differences in $F_{\mathrm{sw}}$ show a decrease as a function of $N_{\mathrm{d}}$ reaching $-75 \mathrm{~W} \mathrm{~m}^{-2}$ at $N_{\mathrm{d}}=100 \mathrm{~cm}^{-3}$. The distribution of differences in $F_{\text {lw }}$ show a slight increase as a function of $N_{\mathrm{d}}$. This can be explained by the less effective sedimentation of the smaller ice crystals which can cause a slight increase in the ice water path.

The temporal evolution of the median effective radii of cloud droplets, $r_{\mathrm{c}}$, and ice crystals, $r_{\mathrm{i}}$, calculated for domain $D 1$, in simulation $\mathrm{C}$ and REF is shown in Fig. 12. For $r_{\mathrm{c}}$ slightly lower values occur in case $\mathrm{C}$ with maximum differences to case REF mostly lower than $1 \mu \mathrm{m}$. In contrast, $r_{\mathrm{i}}$ is significantly lower in simulation $C$ on the order of $10-25 \mu \mathrm{m}$. The difference in $r_{\mathrm{i}}$ scales with the time evolution of the magnitude of $r_{\mathrm{i}}$. Small $r_{\mathrm{i}}$ indicate that ice clouds occur mainly at 

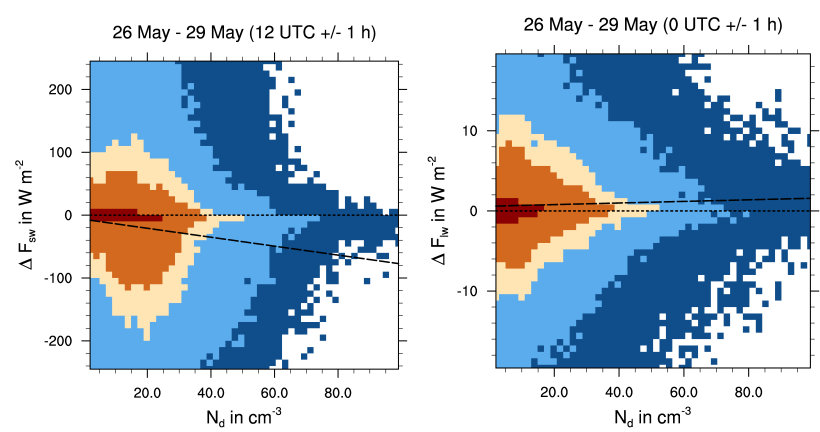

Frequence of occurrence $\%$

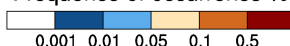

Fig. 11. Joint PDFs of differences (C minus REF) in surface net shortwave radiation flux around noon (left) and in surface net longwave radiation flux around midnight (right) together with average dust concentration at grid points containing cloud ice (C). The dashed line is the result of a linear regression fit of the data.

greater heights, where the difference in $r_{\mathrm{i}}$ is much smaller due to the controlling influence of homogeneous freezing.

Figure 13 shows the temporal evolution of domain averaged cloud properties and radiation fluxes in simulation $\mathrm{C}$ and REF. The temporal evolution of averaged vertical integrated cloud water content, LWP, and ice water content, IWP, shows values of similar magnitude in simulation $\mathrm{C}$ and REF with positive and negative difference of a few percent. Whereas LWP shows most of the time slightly lower values and IWP slightly higher values in case C. Differences in LWP and IWP are mainly caused by differences in the dynamics of the cloud systems. The average in-cloud vertical velocity, $w_{\text {cloud }}$, shows slightly higher values in case $\mathrm{C}$ during the first three days of the dust event. This can be explained by more effective glaciation of mixed phase clouds in case $\mathrm{C}$ and the additional release of latent heat. On the last day $w_{\text {cloud }}$ is lower in simulation $\mathrm{C}$ which is also reflected in a lower LWP. In general, differences in dynamics can be driven by different processes, e.g. changes in radiation and consequently temperature caused by modified cloud properties, and are hard to relate directly with a specific individual process.

In both simulations, the average hourly precipitation rate, $R_{1 \mathrm{~h}}$, is almost identical. Difference in $R_{1 \mathrm{~h}}$ scale mostly with the differences in LWP and IWP, e.g. during the last two days of the dust event were the largest differences occur. Despite the almost identical $R_{1 \mathrm{~h}}$, the local differences can be large due to spatial shifts in the distribution of precipitation.

The domain average $F_{\text {sw }}$ shows systematic differences between simulation $\mathrm{C}$ and REF with lower values in simulation C. The maximum $F_{\mathrm{sw}}$ is reduced significantly in case $\mathrm{C}$ by 10 to $20 \mathrm{~W} \mathrm{~m}^{-2}$. The largest difference in $F_{\mathrm{sw}}$ occurs on 27 May with $20 \mathrm{~W} \mathrm{~m}^{-2}$ lower values in case C. During this day the dust amount is highest in the model domain. Because LWP and IWP are almost identical in both simulations, the difference in $F_{\mathrm{sw}}$ can be directly related to the impact of the

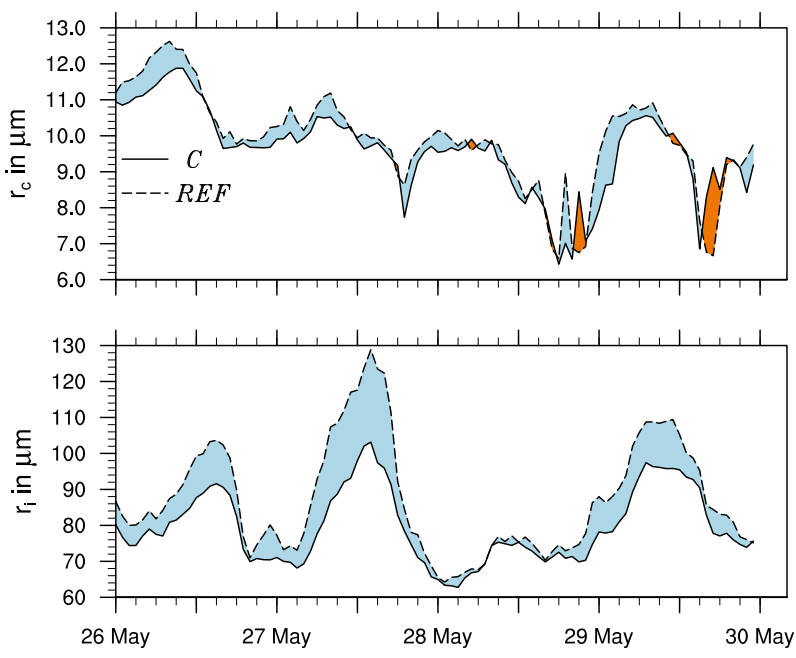

Fig. 12. Time series of the average effective radii of cloud droplets $r_{\mathrm{c}}$ (top) and ice crystal $r_{\mathrm{i}}$ (bottom) of domain D1. Solid lines are results from simulation $\mathrm{C}$ and dashed lines are results from simulation REF. $r_{\mathrm{c}}$ is calculated for gridpoints with a cloud water mass mixing ratio greater than $0.05 \mathrm{~g} \mathrm{~kg}^{-1}$ and $r_{\mathrm{i}}$ for ice crystal mass mixing ratios of more than $0.001 \mathrm{~g} \mathrm{~kg}^{-1}$.

dust particles on the radiative properties of the ice clouds in case $\mathrm{C}$ (Fig. 11). The temporal evolution of the average $F_{\mathrm{lw}}$ shows just small differences between simulation $\mathrm{C}$ and REF with a maximum of $+1.5 \mathrm{~W} \mathrm{~m}^{-2}$.

The difference in the net radiation fluxes at the surface have an impact on the simulated temperatures. The domain averaged daily temperature maximum of the temperature in a height of $2 \mathrm{~m}$ above ground, $T_{2 \mathrm{~m}}$ is up to $0.3 \mathrm{~K}$ lower in case $\mathrm{C}$ than in case REF. $T_{2 \mathrm{~m}}$ is lower in case $\mathrm{C}$ until the daily temperature minimum is reached in the early morning, where $T_{2 \mathrm{~m}}$ in both simulations converge again. Despite the small difference in the domain average $T_{2 \mathrm{~m}}$, the differences are locally much larger. This will be discussed in Sect. 4.5.

\subsection{Direct dust impact on radiation}

Until now we investigated only the impact of dust on the atmospheric state due to the interaction of dust particles with cloud microphysical and optical properties. During the dust event the dust particles interact also directly with the radiation fields of the atmosphere due to scattering and absorption of short and longwave radiation. Results of simulation R, which considers only the direct interaction of dust particles with radiation, and simulation CR, which includes additionally to the interaction with the clouds also the direct interaction of dust particles with radiation, are shown together with the results of simulation C and REF in Fig. 13. The domain averaged dust optical depth at a wavelength of $550 \mathrm{~nm}, \tau_{\text {dust }}$, increases during the dust event up to 0.36 at the 27 May. During the last two days of the dust event $\tau_{\text {dust }}$ decreases again to 0.1 . The additional direct interaction of the dust particles 

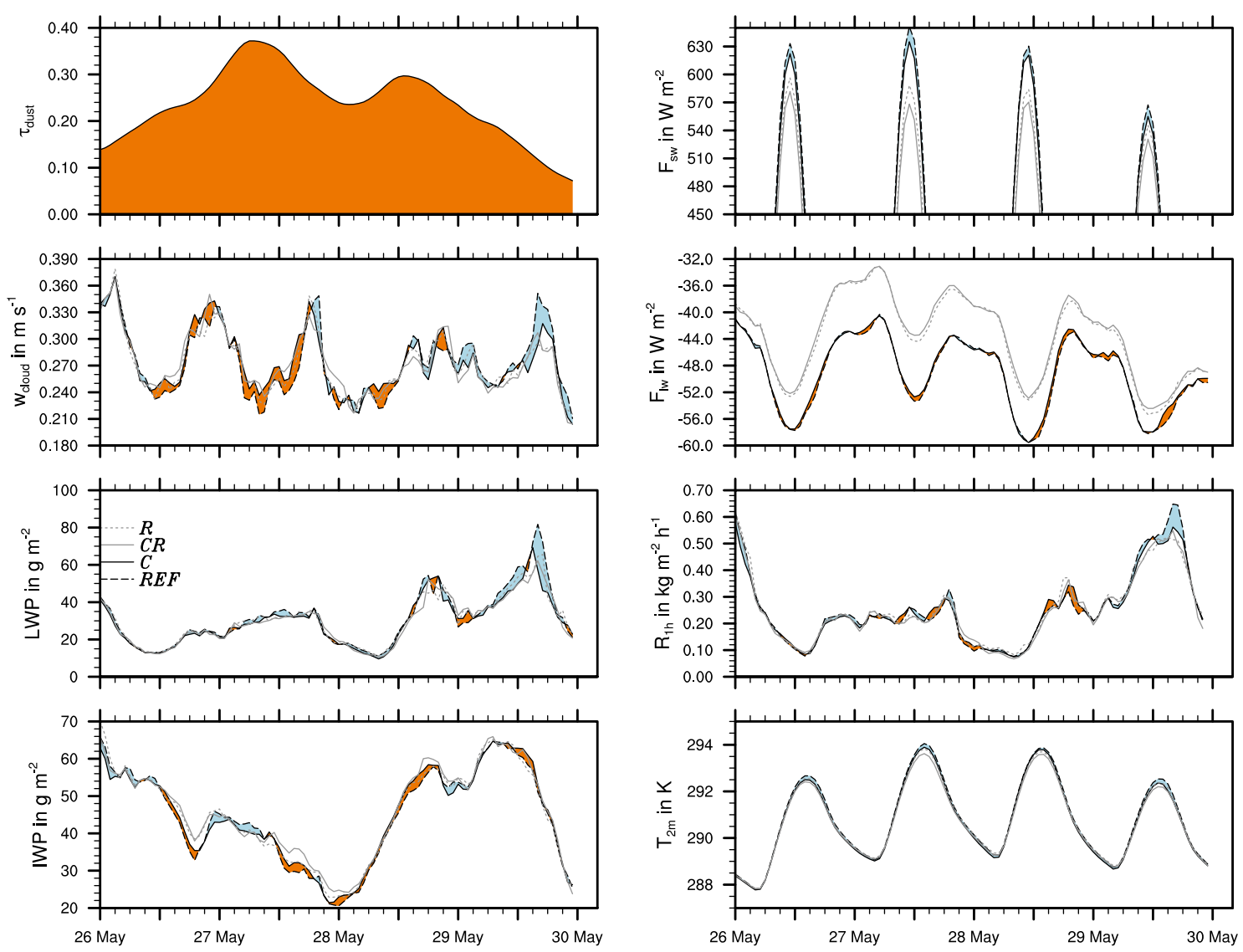

Fig. 13. Time series of dust optical thickness $\left(\tau_{\text {dust }}\right)$, cloud properties ( $w_{\text {cloud }}$, LWP, and IWP), precipitation rate $\left(R_{1 \mathrm{~h}}\right)$, net surface radiation fluxes $\left(F_{\mathrm{sw}}\right.$ and $\left.F_{\mathrm{lw}}\right)$, and temperature $\left(T_{2 \mathrm{~m}}\right)$ averaged for domain D1. Solid lines are results from simulation C, dashed lines are results from simulation REF, solid gray lines are results from simulation $\mathrm{CR}$, and dotted gray lines from simulation $\mathrm{R}$.

with radiation in case $\mathrm{CR}$ causes lower values of $F_{\mathrm{sw}}$ of up to $-80 \mathrm{~W} \mathrm{~m}^{-2}$ at 27 May in comparison to case REF. On the other days of the dust event the maximum $F_{\mathrm{Sw}}$ is 40 to $60 \mathrm{~W} \mathrm{~m}^{-2}$ lower in case CR with respect to case REF. Due to the interaction of the dust particles with the long wave radiation $F_{\text {lw }}$ is in the order of 3 to $10 \mathrm{~W} \mathrm{~m}^{-2}$ higher in case $\mathrm{CR}$ in comparison to the cases $\mathrm{C}$ and REF. The differences in $F_{\mathrm{Sw}}$ and $F_{\mathrm{lw}}$ between case $\mathrm{CR}$ and case $\mathrm{C}$ and the differences between case $\mathrm{R}$ and case REF are consistent. This shows that changes in cloud cover and cloud properties induced by the direct interaction of the dust with radiation are negligible in the presented case. The direct impact of the dust particles in simulation CR causes lower daily maxima of $T_{2 \mathrm{~m}}$ when compared to simulation $\mathrm{C}$. The domain averaged $T_{2 \mathrm{~m}}$ is $0.5 \mathrm{~K}$ lower in CR in comparison to REF at the 27 May. During the night $T_{2} \mathrm{~m}$ converge in the different simulations and get even slightly higher values of $T_{2 \mathrm{~m}}$ in case CR in comparison to $\mathrm{C}$ due to the higher values of $F_{\mathrm{lw}}$. The temperature decreases during the day in $\mathrm{R}$ in comparison with REF (by the direct radiative impact of dust) and in $\mathrm{C}$ (by the interaction of dust with the cloud properties) in comparison to REF are comparable in magnitude. The sum of both effects is compa- rable with the temperature decrease in $\mathrm{CR}$ in comparison to REF (by the combined direct radiative impact of dust and the interaction of dust with the cloud properties).

Whether the direct impact on the radiation or the interaction with the clouds has the larger impact on the domain averaged $T_{2 \mathrm{~m}}$ varies from day to day depending on the spatial distribution of clouds and dust particles.

\subsection{Impact on $T_{2 m}$}

In Fig. 14 the impact of the dust on average $T_{2 \mathrm{~m}}$ is depicted for interaction with cloud properties only (C minus REF) and for direct interaction with radiation together with the interaction with cloud properties (CR minus REF) for the whole model domain. The $T_{2 \mathrm{~m}}$ for case $\mathrm{C}$ at noon is systematically lower over the continent by -0.2 to $-1 \mathrm{~K}$. Isolated areas where $T_{2 \mathrm{~m}}$ in case $\mathrm{C}$ is higher than in case REF can be attributed to small spatial and temporal differences in the distribution of the clouds. The difference in $T_{2 \mathrm{~m}}$ at midnight is lower in comparison to noon time. The $T_{2 \mathrm{~m}}$ at midnight in case $\mathrm{C}$ is lower by -0.1 to $-0.4 \mathrm{~K}$ over the continent. The maximum difference is in the eastern part of France. 


\section{C - REF}
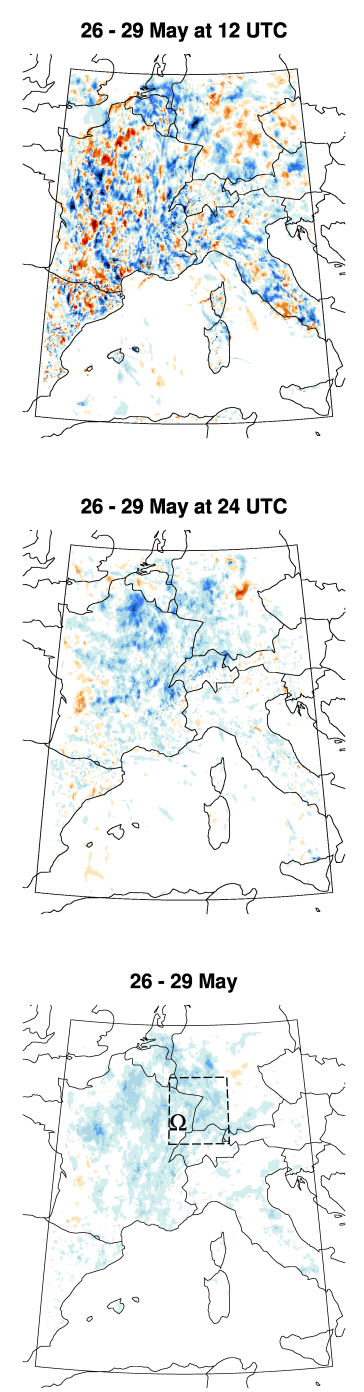

CR - REF
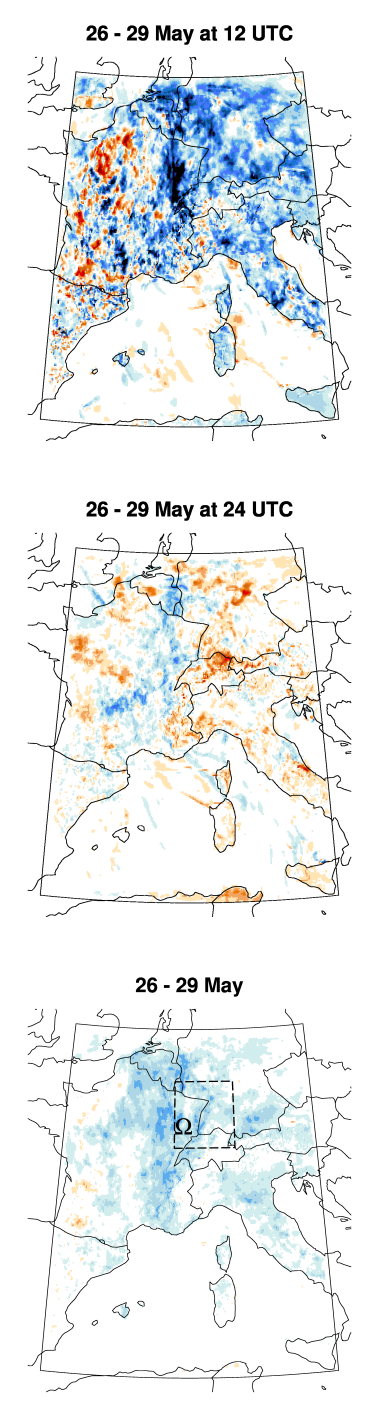

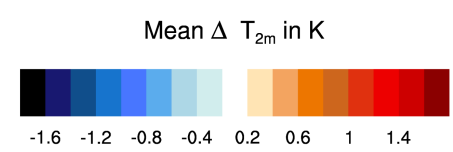

Fig. 14. Mean difference in $T_{2} \mathrm{~m}$ at 12:00 UTC and 24:00 UTC from 26-29 May 2008 and total mean difference in $T_{2 \mathrm{~m}}$ from 26-29 May 2008 between simulation $\mathrm{C}$ and REF (left column) and simulation $\mathrm{CR}$ and REF (right column).

On average over the whole dust event (26-29 May) $T_{2 \mathrm{~m}}$ in case $\mathrm{C}$ is systematically lower than in case REF by -0.2 to $-0.5 \mathrm{~K}$ over the continent. The maximum differences in $T_{2 \mathrm{~m}}$ are in the areas of the maximum average dust concentrations (Fig. 6).

The average difference in $T_{2 \mathrm{~m}}$ from combined interaction of dust with clouds and radiation (difference between simulation $\mathrm{CR}$ and REF) shows negative values during noon time

of up to $-1.8 \mathrm{~K}$ in the areas of the maximum dust concentrations. During midnight, the average difference in $T_{2 \mathrm{~m}}$ is only negative in the areas with a high negative difference during daytime. In all other areas the difference is slightly positive with values up to $+1 \mathrm{~K}$ locally. The average difference in $T_{2 \mathrm{~m}}$ between the simulations CR and REF calculated for the whole period of the dust event shows systematically negative values in the order of $-0.2 \mathrm{~K}$ for the whole continent with maxima up to $-1 \mathrm{~K}$ locally.

As mentioned before, an analysis of the weather forecast results for SW-Germany showed too high $T_{2 \mathrm{~m}}$ (by up to $+2 \mathrm{~K}$ ) in comparison with station observations in the afternoon during the dust event. In the early morning hours, the predicted $T_{2 \mathrm{~m}}$ converged with the observations (Fig. 1).

In Fig. 15 the temporal evolution of the simulated $T_{2 \mathrm{~m}}$ averaged over an area including SW-Germany, $\Omega$, is shown for the cases REF, C, R, and CR. The differences in $T_{2 \mathrm{~m}}$ between $\mathrm{C}, \mathrm{R}$, and $\mathrm{CR}$ and REF reach their maximum values in the afternoon. In the early morning hours $T_{2 \mathrm{~m}}$ in the different simulations converge again. Beside the $28 \mathrm{May}, T_{2 \mathrm{~m}}$ in case $\mathrm{R}$ is higher (+0.1 K to $+0.3 \mathrm{~K}$ ) during the night in comparison to REF due to the higher incoming longwave radiation at the surface (Fig. 13). The differences between $\mathrm{C}$ and REF, and $\mathrm{R}$ and REF are of similar magnitude during day time, whereas the impact of dust on $T_{2 \mathrm{~m}}$ was dominated by the interaction of dust with clouds at the 26 May and 29 May and by the direct interaction of dust with radiation at the 27 May and 28 May. The difference between CR and REF reaches $-0.65 \mathrm{~K}$ to $-1 \mathrm{~K}$ at the afternoon, which is consistent with the sum of the differences between $\mathrm{R}$ and REF, and $\mathrm{C}$ and REF most of the time. This indicates that feedbacks between the direct radiation impact of dust and clouds are of minor importance in this case.

The simulation results presented in this study indicate that the bias in the operational weather forecast can be attributed to the missing interaction of the dust particles with clouds and radiation. Although the observed bias of $T_{2 \mathrm{~m}}$ in the weather forecast is two times larger than the simulated maximum difference in $T_{2 \mathrm{~m}}$ in the area $\Omega$; the daily cycles are comparable. The differences in the magnitude can be explained by uncertainties in the cloud cover and in the exact position of the dust plume; e.g. the differences in $T_{2 \mathrm{~m}}$ in Eastern France reach magnitudes comparable to the observed bias.

Both processes (the interaction with clouds and the direct interaction with the radiation) contribute in a similar magnitude to the simulated differences in $T_{2 \mathrm{~m}}$. Whether the direct impact on the radiation or the interaction with the clouds has the bigger impact on $T_{2 \mathrm{~m}}$ varies depending on e.g. the spatial distribution of clouds and dust particles. 

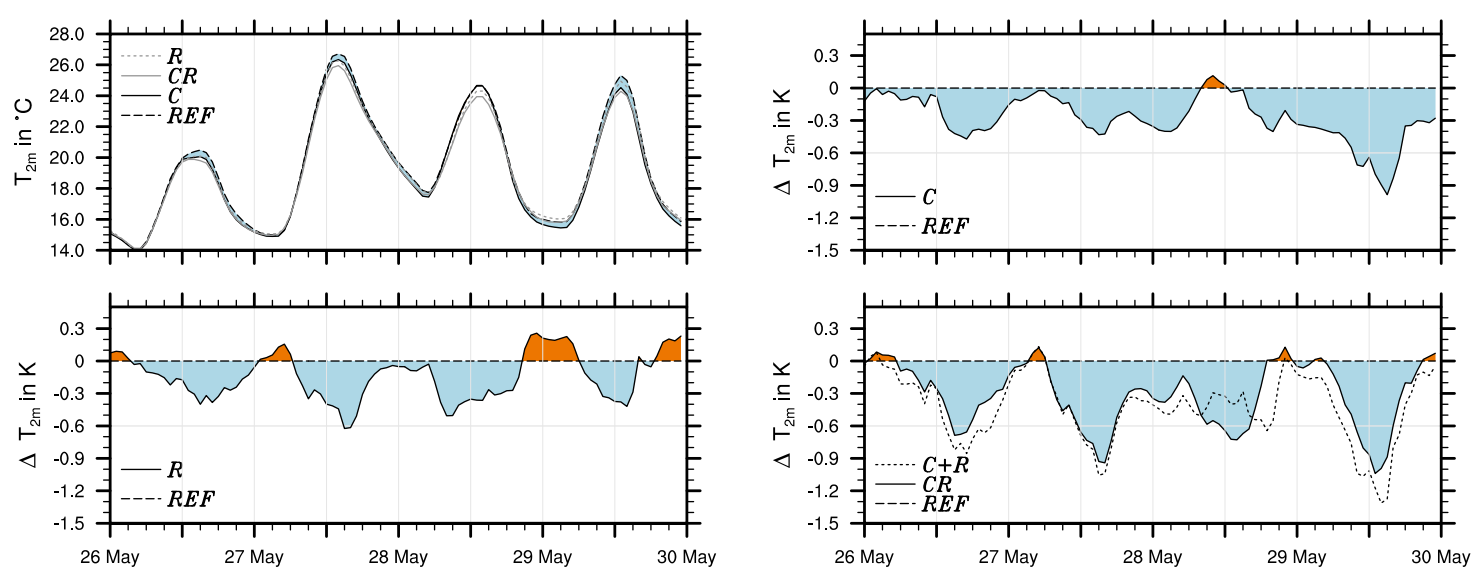

Fig. 15. Temporal evolution of $T_{2 \mathrm{~m}}$ as simulated by the different simulations (top left) and difference in $T_{2} \mathrm{~m}$ of the individual simulations with respect to case REF for area $\Omega$ (see Fig. 14). Additionally to the difference between CR and REF (bottom right) the sum of the differences between $\mathrm{R}$ and $\mathrm{REF}$, and between $\mathrm{C}$ and $\mathrm{REF}$ is shown (dotted line, $\mathrm{C}+\mathrm{R}$ ).

\section{Conclusions}

We investigated the impact of mineral dust particles on clouds, radiation, and atmospheric state during a strong Saharan dust event over Europe in May 2008, applying a comprehensive online-coupled regional model framework that explicitly treats particle microphysics and chemical composition. Sophisticated parameterizations for aerosol activation and ice nucleation, together with two-moment cloud microphysics are used to calculate the interaction of the different particles with clouds depending on their physical and chemical properties.

It is shown that the model framework is able to reproduce the measured aerosol mass concentrations during the dust event reasonably well and capture the aerosol background before the arrival of the dust, as well as the spatial distributions of the clouds in comparison with satellite measurements. Dust particles act as CCN and IN in the atmosphere and can interact with clouds in several ways depending on the atmospheric conditions and cloud type.

For temperatures lower than the level of homogeneous freezing the dust particles have to compete with the homogeneous freezing of liquid aerosol particles for water vapor during the ice nucleation. Though the concentration of frozen dust particles is up to $1001^{-1}$ during the ice nucleation events we found no significant impact on the number and mass concentration of ice crystals in this temperature range.

The impact of the dust on cloud droplet number concentration was found to be low, with just a slight increase in cloud droplet number concentration for both uncoated and coated dust. The number of activated dust particles was found to be in the order of 1 to $20 \mathrm{~cm}^{-3}$, with higher numbers in the case of the coated dust particles. The additional activation of dust particles caused lower maximum supersaturations during the activation process, especially in the case of the coated dust particles.

Mineral dust particles are found to have the largest impact on clouds in a temperature range between freezing level and the level of homogeneous freezing, where they determine the number concentration of ice crystals due to efficient heterogeneous freezing of the dust particles and modify the glaciation of mixed phase clouds. Our simulations show that during the dust events ice crystals concentrations were increased twofold in this temperature range in comparison to a reference simulations which neglects the interaction of the dust with the atmosphere. As a consequence the liquid water fraction was reduced significantly with $60 \%$ less grid points containing cloud water in the temperature range between $263 \mathrm{~K}$ to $235 \mathrm{~K}$.

The strong increase in ice crystal number concentration has an influence on the optical properties of the ice clouds during the time of the dust event due to a significant decrease of effective radii of the ice crystals in the order of up to $-25 \mu \mathrm{m}$ on average. It was shown that depending on the number concentration of dust available for ice nucleation the incoming short-wave radiation at the surface was reduced up to $-75 \mathrm{~W} \mathrm{~m}^{-2}$ at $N_{\mathrm{d}}=100 \mathrm{~cm}^{-3}$. Consequently, a reduction in surface temperature in the order of up to $1 \mathrm{~K}$ over Europe during the day time arises from aerosol-cloud interactions. In the morning hours, the surface temperatures converge again between the different simulations. On average over the whole period of the dust event a reduction in surface temperature in the order of $-0.2 \mathrm{~K}$ to $-0.4 \mathrm{~K}$ was found in the eastern part of France and Western Germany.

The simulated aerosol optical thickness of the dust particles was found to be in the order of 0.2 to 0.5 on average during the dust event over Europe. This caused an additional reduction in the incoming short-wave radiation which was found to be in the order of $-80 \mathrm{~W} \mathrm{~m}^{-2}$ on 27 May. On the 
other days of the event the reduction was found to be in the order of -40 to $-60 \mathrm{~W} \mathrm{~m}^{-2}$. In contrast to the aerosol-cloud interaction only, the incoming long-wave radiation at the surface was increased significantly in the order of $+10 \mathrm{~W} \mathrm{~m}^{-2}$.

The direct impact on radiation together with the impact on the clouds caused lower surface temperatures of up to $-1.8 \mathrm{~K}$ in the areas of the maximum dust concentrations during the daytime. Due to the enhanced incoming long-wave radiation a temperature increase was found for most parts of Europe during the night time. Only in the areas with the maximum temperature difference during the day the night temperatures were still below the ones simulated neglecting the interaction of dust with the atmosphere.

On average the overall impact of the dust caused a reduction in surface temperature in the order of -0.2 to $-0.5 \mathrm{~K}$ for most parts of France, Germany, and Italy during the dust event. The maximum difference in surface temperature was found in the East of France, the Benelux, and Western Germany with up to $-1 \mathrm{~K}$.

The simulations suggest that the bias which was found in numerical weather forecast during the period of the dust event can be explained by the missing aerosol cloud interaction in current weather forecast simulations. Weather forecast models use climatological aerosol conditions to represent AOT and calculate ice crystal and clouds droplet number concentrations. Hence they are not able to represent conditions which differ significantly from the climatological values, which is the case during strong dust events over Europe.

Acknowledgements. We thank H. Flentje (DWD) for providing the $\mathrm{PM}_{10}$ measurement data and U. Damrath (DWD) for providing the forecast validation information. We gratefully acknowledge A. Seifert (DWD) for his support with his cloud microphysic scheme, E. Zubler (ETH) for providing the code for the improved parametrization of cloud optical properties, and R. Frey (UWMadison) for his information on the MODIS cloud product. This work was supported by the Karlsruhe House of Young Scientist (KHYS). AN, DB, VK and PK acknowledge support from an NSF CAREER award, and grants from NASA MAP, NASA ACMAP and NOAA OGP. We acknowledge support by Deutsche Forschungsgemeinschaft and Open Access Publishing Fund of Karlsruhe Institute of Technology.

Edited by: N. Riemer

\section{References}

Alfaro, S. and Gomes, L.: Modeling mineral aerosol production by wind erosion: Emission intensities and aerosol size distributions in source areas, J. Geophys. Res.-Atmos., 106, 18075-18084, doi:10.1029/2000JD900339, 2001.

Ansmann, A., Bosenberg, J., Chaikovsky, A., Comeron, A., Eckhardt, S., Eixmann, R., Freudenthaler, V., Ginoux, P., Komguem, L., Linne, H., Marquez, M., Matthias, V., Mattis, I., Mitev, V., Muller, D., Music, S., Nickovic, S., Pelon, J., Sauvage, L., Sobolewsky, P., Srivastava, M., Stohl, A., Torres, O., Vaughan, G., Wandinger, U., and Wiegner, M.: Long-range transport of
Saharan dust to northern Europe: The 11-16 October 2001 outbreak observed with EARLINET, J. Geophys. Res.-Atmos., 108, 4783, doi:10.1029/2003JD003757, 2003.

Baldauf, M., Seifert, A., Förstner, J., Majewski, D., Raschendorfer, M., and Reinhardt, T.: Operational convective-scale numerical weather prediction with the COSMO model: description and sensitivities, Mon. Weather Rev., 139, 3887-3905, doi:10.1175/MWR-D-10-05013.1, e-View, 2011.

Bangert, M., Kottmeier, C., Vogel, B., and Vogel, H.: Regional scale effects of the aerosol cloud interaction simulated with an online coupled comprehensive chemistry model, Atmos. Chem. Phys., 11, 4411-4423, doi:10.5194/acp-11-4411-2011, 2011.

Barahona, D. and Nenes, A.: Parameterization of cirrus cloud formation in large-scale models: homogeneous nucleation, J. Geophys. Res.-Atmos., 113, D11211, doi:10.1029/2007JD009355, 2008.

Barahona, D. and Nenes, A.: Parameterizing the competition between homogeneous and heterogeneous freezing in cirrus cloud formation - monodisperse ice nuclei, Atmos. Chem. Phys., 9, 369-381, doi:10.5194/acp-9-369-2009, 2009a.

Barahona, D. and Nenes, A.: Parameterizing the competition between homogeneous and heterogeneous freezing in ice cloud formation - polydisperse ice nuclei, Atmos. Chem. Phys., 9, 59335948, doi:10.5194/acp-9-5933-2009, 2009b.

Barahona, D., West, R. E. L., Stier, P., Romakkaniemi, S., Kokkola, H., and Nenes, A.: Comprehensively accounting for the effect of giant $\mathrm{CCN}$ in cloud activation parameterizations, Atmos. Chem. Phys., 10, 2467-2473, doi:10.5194/acp-10-24672010, 2010a.

Barahona, D., Rodriguez, J., and Nenes, A.: Sensitivity of the global distribution of cirrus ice crystal concentration to heterogeneous freezing, J. Geophys. Res.-Atmos., 115, D23213, doi:10.1029/2010JD014273, 2010b.

Blahak, U.: Towards a Better Representation of High Density Ice Particles in a State-of-the-Art Two-Moment Bulk Microphysical Scheme, Extended Abstract, International Conference on Clouds and Precipitation, Cancun, 7-11 July 2008, available at: http://cabernet.atmosfcu.unam.mx/ICCP-2008/abstracts/ Program_on_line/Poster_07/Blahak_extended_1.pdf (last access: 30 November 2011), 2008.

Cantrell, W. and Heymsfield, A.: Production of ice in tropospheric clouds - a review, B. A. M. Meteorol. Soc., 86, 795-807, doi:10.1175/BAMS-86-6-795, 2005.

Cavazos, C., Todd, M. C., and Schepanski, K.: Numerical model simulation of the Saharan dust event of 6-11 March 2006 using the Regional Climate Model version 3 (RegCM3), J. Geophys Res.-Atmos., 114, D12109, doi:10.1029/2008JD011078, 2009.

Chaboureau, J.-P., Richard, E., Pinty, J.-P., Flamant, C., Di Girolamo, P., Kiemle, C., Behrendt, A., Chepfer, H., Chiriaco, M., and Wulfmeyer, V.: Long-range transport of Saharan dust and its radiative impact on precipitation forecast: a case study during the convective and Orographically-induced Precipitation Study (COPS), Q. J. Roy. Meteor. Soc., 137, 236-251, doi:10.1002/qj.719, 2011.

D'Almeida, G. A.: A model for Saharan dust transport, J. Clim. Appl. Meteorol., 25, 903-916, doi:10.1175/15200450(1986)025;0903:AMFSDT ¿2.0.CO;2, 1986.

Doms, G., Förstner, J., Heise, E., Herzog, H.-J., and Raschendorfer, M.: Nonhydrostatic Regional Model LM, Part II: Physi- 
cal Parameterization, Tech. Rep., Deutscher Wetterdienst, Offenbach, 2005.

Edwards, J. M., Havemann, S., Thelen, J.-C., and Baran, A. J.: A new parametrization for the radiative properties of ice crystals: comparison with existing schemes and impact in a GCM, Atmos. Res., 83, 19-35, doi:10.1016/j.atmosres.2006.03.002, 2007.

EEA, 2011: Airbase - the european air quality database. Tech. rep., European Environment Agency, Copenhagen, www.eea.europa.eu/data-and-maps/data/ airbase-the-european-air-quality-database.

Emmons, L. K., Walters, S., Hess, P. G., Lamarque, J.-F., Pfister, G. G., Fillmore, D., Granier, C., Guenther, A., Kinnison, D., Laepple, T., Orlando, J., Tie, X., Tyndall, G., Wiedinmyer, C., Baughcum, S. L., and Kloster, S.: Description and evaluation of the Model for Ozone and Related chemical Tracers, version 4 (MOZART-4), Geosci. Model Dev., 3, 43-67, doi:10.5194/gmd3-43-2010, 2010.

Field, P. R., Möhler, O., Connolly, P., Krämer, M., Cotton, R., Heymsfield, A. J., Saathoff, H., and Schnaiter, M.: Some ice nucleation characteristics of Asian and Saharan desert dust, Atmos. Chem. Phys., 6, 2991-3006, doi:10.5194/acp-6-2991-2006, 2006.

Goudie, A. and Middleton, N.: Saharan dust storms: nature and consequences, Earth-Sci. Rev., 56, 179-204, doi:10.1016/S0012-8252(01)00067-8, 2001.

Helmert, J., Heinold, B., Tegen, I., Hellmuth, O., and Wendisch, M.: On the direct and semidirect effects of Saharan dust over Europe: A modeling study, J. Geophys. Res.-Atmos., 112, D13208, doi:10.1029/2006JD007444, 2007.

Hoose, C., Lohmann, U., Erdin, R., and Tegen, I.: The global influence of dust mineralogical composition on heterogeneous ice nucleation in mixed-phase clouds, Environ. Res. Lett., 3, 025003 , doi:10.1088/1748-9326/3/2/025003, 2008.

$\mathrm{Hu}, \mathrm{Y} . \mathrm{X}$. and Stamnes, K.: An accurate parameterization of the radiative properties of water clouds suitable for use in climate models, J. Climate, 6, 728-742, 1993.

Karydis, V., Kumar, P., Barahona, D., and Nenes, A.: On the effect of insoluble dust particles on global CCN and droplet number, J. Geophys. Res., 116, D23204, doi:10.1029/2011JD016283, 2011.

Klein, H., Nickovic, S., Haunold, W., Bundke, U., Nillius, B., Ebert, M., Weinbruch, S., Schuetz, L., Levin, Z., Barrie, L. A., and Bingemer, H.: Saharan dust and ice nuclei over Central Europe, Atmos. Chem. Phys., 10, 10211-10221, doi:10.5194/acp10-10211-2010, 2010.

Knote, C., Brunner, D., Vogel, H., Allan, J., Asmi, A., Äijälä, M., Carbone, S., van der Gon, H. D., Jimenez, J. L., KiendlerScharr, A., Mohr, C., Poulain, L., Prévôt, A. S. H., Swietlicki, E., and Vogel, B.: Towards an online-coupled chemistry-climate model: evaluation of trace gases and aerosols in COSMO-ART, Geosci. Model Dev., 4, 1077-1102, doi:10.5194/gmd-4-10772011, 2011.

Koop, T., Luo, B. P., Tsias, A., and Peter, T.: Water activity as the determinant for homogeneous ice nucleation in aqueous solutions, Nature, 406, 611-614, 2000.

Kumar, P., Sokolik, I. N., and Nenes, A.: Parameterization of cloud droplet formation for global and regional models: including adsorption activation from insoluble CCN, Atmos. Chem. Phys., 9, 2517-2532, doi:10.5194/acp-9-2517-2009, 2009.
Kumar, P., Sokolik, I. N., and Nenes, A.: Measurements of cloud condensation nuclei activity and droplet activation kinetics of fresh unprocessed regional dust samples and minerals, Atmos. Chem. Phys., 11, 3527-3541, doi:10.5194/acp-11-3527-2011, 2011.

Levin, Z., Ganor, E., and Gladstein, V.: The effects of desert particles coated with sulfate on rain formation in the Eastern Mediterranean, J. Appl. Meteorol., 35, 1511-1523, 1996.

Lohmann, U. and Diehl, K.: Sensitivity studies of the importance of dust ice nuclei for the indirect aerosol effect on stratiform mixedphase clouds, J. Atmos. Sci., 63, 968-982, 2006.

Lowell, S., Shields, J. E., Thomas, M. A., and Thommes, M.: Characterization of porous solids and powders: surface area, pore size and density, in: Particle Technology Series, vol. 16, Kluwer Academic Publishers, Dordrecht, 2004.

Lu, H. and Shao, Y.: A new model for dust emission by saltation bombardment, J. Geophys. Res.-Atmos., 104, 16827-16841, doi:10.1029/1999JD900169, 1999.

Lundgren, K.: Direct Radiative Effects of Sea Salt on the Regional Scale, Ph.D. thesis, Karlsruhe Institute of Technology, Karlsruhe, 2010.

Menzel, W. P., Frey, R. A., Zhang, H., Wylie, D. P., Moeller, C. C., Holz, R. E., Maddux, B., Baum, B. A., Strabala, K. I., and Gumley, L. E.: MODIS global cloud-top pressure and amount estimation: algorithm description and results, J. Appl. Meteorol. Clim., 47, 1175-1198, doi:10.1175/2007JAMC1705.1, 2008.

Min, Q. and Li, R.: Longwave indirect effect of mineral dusts on ice clouds, Atmos. Chem. Phys., 10, 7753-7761, doi:10.5194/acp10-7753-2010, 2010.

Min, Q.-L., Li, R., Lin, B., Joseph, E., Wang, S., Hu, Y., Morris, V., and Chang, F.: Evidence of mineral dust altering cloud microphysics and precipitation, Atmos. Chem. Phys., 9, 3223-3231, doi:10.5194/acp-9-3223-2009, 2009.

Möhler, O., Field, P. R., Connolly, P., Benz, S., Saathoff, H., Schnaiter, M., Wagner, R., Cotton, R., Krämer, M., Mangold, A., and Heymsfield, A. J.: Efficiency of the deposition mode ice nucleation on mineral dust particles, Atmos. Chem. Phys., 6, 30073021, doi:10.5194/acp-6-3007-2006, 2006.

Morales, R. and Nenes, A.: Characteristic updrafts for computing distribution-averaged cloud droplet number, autoconversion rate and effective radius, J. Geophys. Res., 115, D18220, doi:10.1029/2009JD013233, 2010.

Niemand, M., Möhler, O., Vogel, B., Vogel, H., Hoose, C., Connolly, P., Klein, H., Bingemer, H., DeMott, P., Skrotzki, S., and Leisner, T.: Parameterization of immersion freezing on mineral dust particles: an application in a regional scale model, J. Atmos. Sci., in press, 2012.

Noppel, H., Blahak, U., Beheng, K. D., and Seifert, A.: A TwoMoment Cloud Microphysics Scheme with Two ProcessSeparated Modes of Graupel, 12. AMS Conference on Cloud Physics, 10-14 July 2006, Madison, Wisconsin, available at: http://ams.confex.com/ams/pdfpapers/113532.pdf (last access: 30 November 2011), 2006.

Perez, C., Nickovic, S., Pejanovic, G., Baldasano, J. M., and Oezsoy, E.: Interactive dust-radiation modeling: a step to improve weather forecasts, J. Geophys. Res.-Atmos., 111, D16206, doi:10.1029/2005JD006717, 2006.

Phillips, V. T. J., DeMott, P. J., and Andronache, C.: An empirical parameterization of heterogeneous ice nucleation for multi- 
ple chemical species of aerosol, J. Atmos. Sci., 65, 2757-2783, doi:10.1175/2007JAS2546.1, 2008.

Pradelle, F. and Cautenet, G.: Radiative and microphysical interactions between marine stratocumulus clouds and Saharan dust - 2. Modeling, J. Geophys. Res.-Atmos., 107, 4413, doi:10.1029/2000JD000156, 2002.

Pregger, T., Thiruchittampalam, B., and Friedrich, R.: Ermittlung von Emissionsdaten zur Untersuchung der Klimawirksamkeit von Rußpartikeln in Baden-Württemberg, Final report, IER Universität Stuttgart, Stuttgart, 2007.

Pruppacher, H. R. and Klett, J. D.: Microphysics of Clouds and Precipitation, 2nd ed., Kluwer Academic Publishers, Dordrecht, Boston, London, 954 pp., 1997.

Riemer, N., Vogel, B., Vogel, H., and Fiedler, F.: Modeling aerosols on the mesoscale- $\gamma$ : treatment of soot aerosol and its radiative effects, J. Geophys. Res., 108, 4601, doi:10.1029/2003JD003448, 2003.

Ritter, B. and Geleyn, J. F.: A comprehensive radiation scheme for numerical weather prediction models with potential applications in climate simulations, Mon. Weather Rev., 120, 303-325, doi:10.1175/1520-0493(1992)120<0303:ACRSFN > 2.0.CO;2, 1992.

Rosenfeld, D., Rudich, Y., and Lahav, R.: Desert dust suppressing precipitation: a possible desertification feedback loop, P. Natl. Acad. Sci., 98, 5975-5980, doi:10.1073/pnas.101122798, 2001.

Seifert, A. and Beheng, K. D.: A two-moment cloud microphysics parameterization for mixed-phase clouds. Part 1: Model description, Meteorol. Atmos. Phys., 92, 45-66, doi:10.1007/s00703005-0112-4, 2006.

Seifert, A., Khain, A., Pokrovsky, A., and Beheng, K. D.: A comparison of spectral bin and two-moment bulk mixed-phase cloud microphysics, Atmos. Res., 80, 46-66, 2006.

Seifert, P., Ansmann, A., Mattis, I., Wandinger, U., Tesche, M., Engelmann, R., Mueller, D., Perez, C., and Haustein, K.: Saharan dust and heterogeneous ice formation: Eleven years of cloud observations at a Central European EARLINET site, J. Geophys. Res., 115, D20201, doi:10.1029/2009JD013222, 2010.

Seifert, A., Köhler, C., and Beheng, K. D.: Aerosol-cloudprecipitation effects over Germany as simulated by a convectivescale numerical weather prediction model, Atmos. Chem. Phys. Discuss., 11, 20203-20243, doi:10.5194/acpd-11-20203-2011, 2011.

Solomos, S., Kallos, G., Kushta, J., Astitha, M., Tremback, C., Nenes, A., and Levin, Z.: An integrated modeling study on the effects of mineral dust and sea salt particles on clouds and precipitation, Atmos. Chem. Phys., 11, 873-892, doi:10.5194/acp11-873-2011, 2011.
Sorjamaa, R. and Laaksonen, A.: The effect of $\mathrm{H}_{2} \mathrm{O}$ adsorption on cloud drop activation of insoluble particles: a theoretical framework, Atmos. Chem. Phys., 7, 6175-6180, doi:10.5194/acp-76175-2007, 2007.

Stanelle, T., Vogel, B., Vogel, H., Bäumer, D., and Kottmeier, C.: Feedback between dust particles and atmospheric processes over West Africa during dust episodes in March 2006 and June 2007, Atmos. Chem. Phys., 10, 10771-10788, doi:10.5194/acp-1010771-2010, 2010.

Sullivan, R. C., Guazzotti, S. A., Sodeman, D. A., and Prather, K. A.: Direct observations of the atmospheric processing of Asian mineral dust, Atmos. Chem. Phys., 7, 1213-1236, doi:10.5194/acp-7-1213-2007, 2007.

Swap, R., Ulanski, S., Cobbett, M., and Garstang, M.: Temporal and spatial characteristics of Saharan dust outbreaks, J. Geophys. Res.-Atmos., 101, 4205-4220, doi:10.1029/95JD03236, 1996.

Tegen, I.: Modeling the mineral dust aerosol cycle in the climate system, Quaternary Sci. Rev., 22, 1821-1834, doi:10.1016/S0277-3791(03)00163-X, 2003.

Tiedtke, M.: A comprehensive mass flux scheme for cumulus parameterization in large-scale models, Mon. Weather Rev., 117, 1779-1800, 1989.

Vogel, B., Hoose, C., Vogel, H., and Kottmeier, C.: A model of dust transport applied to the Dead Sea Area, Meteorol. Z., 15, 611-624, doi:10.1127/0941-2948/2006/0168, 2006.

Vogel, B., Vogel, H., Bäumer, D., Bangert, M., Lundgren, K., Rinke, R., and Stanelle, T.: The comprehensive model system COSMO-ART - Radiative impact of aerosol on the state of the atmosphere on the regional scale, Atmos. Chem. Phys., 9, 86618680, doi:10.5194/acp-9-8661-2009, 2009.

Waliser, D. E., Li, J. L. F., L'Ecuyer, T. S., and Chen, W. T.: The impact of precipitating ice and snow on the radiation balance in global climate models, Geophys. Res. Lett., 38, L06802, doi:10.1029/2010GL046478, 2011.

Wiacek, A., Peter, T., and Lohmann, U.: The potential influence of Asian and African mineral dust on ice, mixed-phase and liquid water clouds, Atmos. Chem. Phys., 10, 8649-8667, doi:10.5194/acp-10-8649-2010, 2010.

Yin, Y. and Chen, L.: The effects of heating by transported dust layers on cloud and precipitation: a numerical study, Atmos. Chem. Phys., 7, 3497-3505, doi:10.5194/acp-7-3497-2007, 2007.

Zubler, E. M., Folini, D., Lohmann, U., Lüthi, D., Muhlbauer, A., Pousse-Nottelmann, S., Schär, C., and Wild, M.: Implementation and evaluation of aerosol and cloud microphysics in a regional climate model, J. Geophys. Res., 116, D02211, doi:10.1029/2010JD014572, 2011. 